\title{
Dynamic adjustment of climatological ozone boundary conditions for air-quality forecasts
}

\author{
P. A. Makar ${ }^{1}$, W. Gong ${ }^{1}$, C. Mooney ${ }^{2}$, J. Zhang ${ }^{1}$, D. Davignon ${ }^{3}$, M. Samaali ${ }^{3}$, M. D. Moran ${ }^{1}$, H. He ${ }^{1}$, D. W. Tarasick ${ }^{1}$, \\ D. Sills ${ }^{4}$, and J. Chen ${ }^{3}$ \\ ${ }^{1}$ Air Quality Research Division, Science and Technology Branch, Environment Canada, 4905 Dufferin Street, Toronto, \\ Ontario, M3H 5T4, Canada \\ ${ }^{2}$ Air Quality Science Unit, Environment Canada, Edmonton, Alberta, Canada \\ ${ }^{3}$ Air Quality Modelling Applications Section, Environment Canada, 2121 TransCanada Highway, Dorval, \\ Quebec, H9P 1J3, Canada \\ ${ }^{4}$ Cloud Physics and Severe Weather Research Section, Environment Canada, 4905 Dufferin Street, Toronto, Ontario, Canada
}

Received: 3 May 2010 - Published in Atmos. Chem. Phys. Discuss.: 1 June 2010

Revised: 27 August 2010 - Accepted: 1 September 2010 - Published: 28 September 2010

\begin{abstract}
Ten different approaches for applying lateral and top climatological boundary conditions for ozone have been evaluated using the off-line regional air-quality model AURAMS, driven with meteorology provided by the GEM weather-forecast model. All ten approaches employ the same climatological ozone profiles, but differ in the manner in which they are applied, via the inclusion or exclusion of (i) a dynamic adjustment of the climatological ozone profile in response to the model-predicted tropopause height, (ii) a sponge zone for ozone on the model top, (iii) upward extrapolation of the climatological ozone profile, and (iv) different mass consistency corrections. The model performance for each approach was evaluated against North American surface ozone and ozonesonde observations from the BAQSMet field study period in the summer of 2007. The original daily one-hour maximum surface ozone biases of about $+15 \mathrm{ppbv}$ were greatly reduced (halved) in some simulations using alternative methodologies. However, comparisons to ozonesonde observations showed that the reduction in surface ozone bias sometimes came at the cost of significant positive biases in ozone concentrations in the free troposphere and upper troposphere. The best overall performance throughout the troposphere was achieved using a methodology that included dynamic tropopause height adjustment, no sponge zone at the model top, extrapolation of ozone when required above the limit of the climatology, and no mass consistency corrections (global mass conservation was still
\end{abstract}

Correspondence to: P. A. Makar (paul.makar@ec.gc.ca) enforced). The simulation using this model version had a one-hour daily maximum surface ozone bias of $+8.6 \mathrm{ppbv}$, with small reductions in model correlation, and the best comparison to ozonesonde profiles. This recommended and original methodologies were compared for two further case studies: a high-resolution simulation of the BAQS-Met measurement intensive, and a study of the downwind region of the Canadian Rockies. Significant improvements were noted for the high resolution simulations during the BAQSMet measurement intensive period, both in formal statistical comparisons and time series comparisons of events at surface stations. The tests for the downwind-Rockies region showed that the coupling between vertical transport associated with troposphere/stratosphere exchange, and that associated with boundary layer turbulent mixing, may contribute to ozone positive biases. The results may be unique to the modelling setup employed, but the results also highlight the importance of evaluating boundary condition and mass consistency/correction algorithms against three-dimensional datasets.

\section{Introduction}

Regional-scale chemical transport models (CTMs) require the specification of chemical concentrations on their lateral and top boundaries, in order to accurately simulate concentrations of long-lived species within the model domain (e.g. Brost, 1987). Most research to date on this topic has centred on boundary conditions for tropospheric ozone due both to its importance as an air pollutant and to the presence

Published by Copernicus Publications on behalf of the European Geosciences Union. 
of a huge reservoir of ozone in the stratosphere. Accurate forecasting of ozone in the Los Angeles area was shown to be critically dependent on the treatment of ozone at inflow boundaries for regional models studying reactive organic gas and $\mathrm{NO}_{\mathrm{x}}$ control strategies in that area (Winner et al., 1995). Mathur et al. (2005) noted that poor regional CTM ozone performance for free tropospheric ozone could be linked to lateral boundary condition specification, as well as the model boundary layer - free troposphere exchange mechanisms. and the chemical mechanisms used in the models. Simple boundary condition treatments such as "zero-gradient", where the spatial gradients of the chemical species are assumed to be zero on the boundaries, have been shown to be inadequate, but the quality of the data used for non-zerogradient boundary conditions is of key importance (Tarasick et al., 2007; Samaali et al., 2009). Consistent positive biases in regional model ozone simulations have also been linked to lateral boundary condition specification (Yu et al., 2007). In the latter study, the linkage between the boundary conditions and transport and diffusion was found to be critical in improving ozone predictions.

Model performance is considerably improved with the use of time-invariant chemical lateral boundary conditions based on observations, compared to zero-gradient boundary conditions (Samaali et al., 2009). A comparison of regional CTM simulations using predefined, fixed lateral boundary conditions for relatively clean conditions, versus time-dependent boundary-condition values provided by a global model, were compared for the Southern Oxidants Study (Song et al., 2008). The use of the boundary conditions provided by the global model improved the regional CTM's predictions of both diurnal variations and daily maxima of surface ozone concentrations relative to time-invariant, fixed boundary conditions. The global-model-derived boundary conditions also gave better agreement with the observed vertical structure in the middle and upper troposphere. Model simulations using lateral boundary conditions derived from time-invariant sources, global air pollution model simulations, and timevarying ozonesonde data have been compared to observations (Tang et al., 2007, 2009). Correlation coefficients improved with the use of the global CTM output as regional model boundary conditions, but positive mean biases also increased for some of the global models employed, whereas the boundary conditions derived from ozonesondes improved the upper Troposphere ozone correlations. Upper troposphere negative ozone biases such as noted by Tarasick et al. (2007) have been decreased in magnitude through the use of lateral boundary conditions provided by global CTMs (MenaCarrasco et al., 2007). European regional ozone simulations comparing the use of climatological ozone profiles versus time-dependent profiles supplied by global CTM simulations showed a slight improvement in correlation with the use of the latter, but no significant impact on the magnitude of surface ozone peaks, which were found to result from surface ozone chemistry (Szopa et al., 2009). Ozone lateral boundary conditions were found to have a crucial effect on surface level "background concentrations" of ozone, in the same study. Similarly, van Loon et al. (2007) compared seven different regional CTMs, and found that all tended to overestimate daytime ozone concentrations, moreover, for one CTM of the ensemble this was the result of a systematic bias in its ozone boundary conditions. The inclusion of day and nighttime variation in ozone lateral boundary conditions has been shown to improve regional model performance (Chen et al., 2003).

The ozone top boundary condition has been found to have a strong effect on ozone concentrations above $4 \mathrm{~km}$ altitude, and the removal of the time variation of all boundary conditions resulted in a significant bias in variation prediction and sometimes affected the predicted mean (Tang et al., 2007). The use of zero-flux conditions at the top boundary was found to result in a significant negative ozone bias in the upper troposphere due to the resulting exclusion of stratosphere-troposphere exchange events (Tong and Mauzerall, 2006). Such events inject stratospheric ozone into the upper troposphere episodically (cf. Holton et al., 1995; Stohl et al., 2003). Thouret et al. (2006) found that the location of the tropopause was a useful indicator in order to remove synoptic and seasonal variations from ozone climatologies.

An analysis of initial and boundary conditions for ozone simulations of the northeastern Iberian Peninsula has shown that the impact of ozone initial conditions lasts a few days, whereas the impact of ozone boundary conditions remains important throughout a simulation, particularly in regions in which the ozone precursors are dominated by short-tomedium-range transport (Jimenez et al., 2007).

In the current work, we examine the impact on tropospheric ozone forecasts of ten different model configurations. We introduce a new methodology, dynamic tropopause height adjustment, for the use of climatology-based ozone data as regional CTM lateral and top ozone boundary conditions. This methodology uses tropopause-height forecasts at inflow boundaries to perform time-dependent adjustments of the climatological ozone profiles prior to their use as boundary conditions. Tests are performed for three cases; continental scale for North America for the summer of 2007 (BAQSMet monitoring period), at high resolution in Southern Ontario during the BAQS-Met field intensive (cf. Makar et al., 2007), and for a region east of the Canadian Rocky Mountains during the summer of 2002. The tropopause-heightbased dynamic adjustment allows a regional CTM to capture some of the variability of the upper troposphere at the inflow boundaries, and results in significant improvements in both upper and surface ozone simulations, relative to observations.

The work was motivated by the observation that the use of realistic ozone boundary conditions in the place of zerogradient boundary conditions (Samaali et al., 2009), while generally improving model results, can sometimes result in 


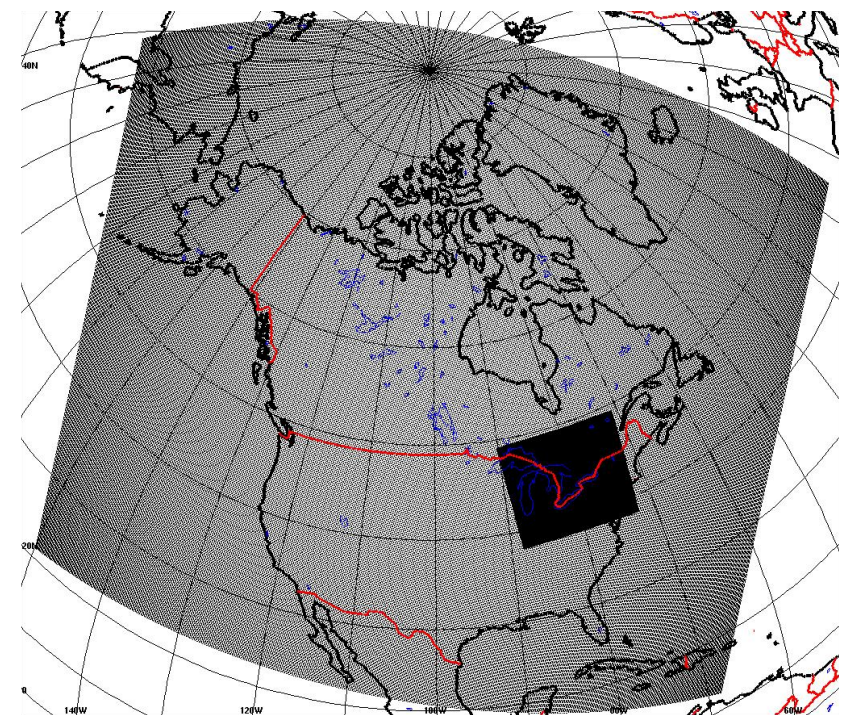

Fig. 1. GEM $15 \mathrm{~km}$ (core portion of global-variable grid shown) and $2.5 \mathrm{~km}$ domains.

erroneously large amounts of ozone being mixed downwards from the tropopause, for the modelling system described in the following section. The use of potential vorticity as a surrogate for upper atmospheric ozone is examined separately (He et al., 2010).

\section{Methodology}

\subsection{Modelling system description}

AURAMS (A Unified Regional Air-quality Modelling System, version 1.4.0) consists of three main components: (a) a prognostic meteorological model, GEM (Global Environmental Multiscale model; Côté et al., 1998); (b) an emissions processing system, SMOKE (Sparse Matrix Operator Kernel Emissions; Houyoux et al., 2000; CEP, 2003) ; and (c) an off-line regional chemical transport model, the AURAMS Chemical Transport Model (CTM; cf. Gong et al., 2006; Cho et al., 2009; Makar et al., 2009; Smyth et al., 2009).

For the simulations of the Border Air-Quality - Meteorology (BAQS-Met) study period (Makar et al., 2010), GEM version 3.2.2 with physics version 4.5 was run on two domains: a variable-resolution, global, horizontal rotated latitude-longitude grid with a uniform core grid covering North America $(575 \times 641$ grid points over the globe, with $432 \times 565$ grid points over North America, $0.1375^{\circ}$ or approximately $15.3 \mathrm{~km}$ grid spacing in the core region, $450 \mathrm{~s}$ time step), and a local domain covering the Great Lakes area $\left(565 \times 494\right.$ grid points, $0.0225^{\circ}$ or approximately $2.5 \mathrm{~km}$ grid spacing, $60 \mathrm{~s}$ time step). The coarse resolution domain output was used to provide boundary conditions for the high

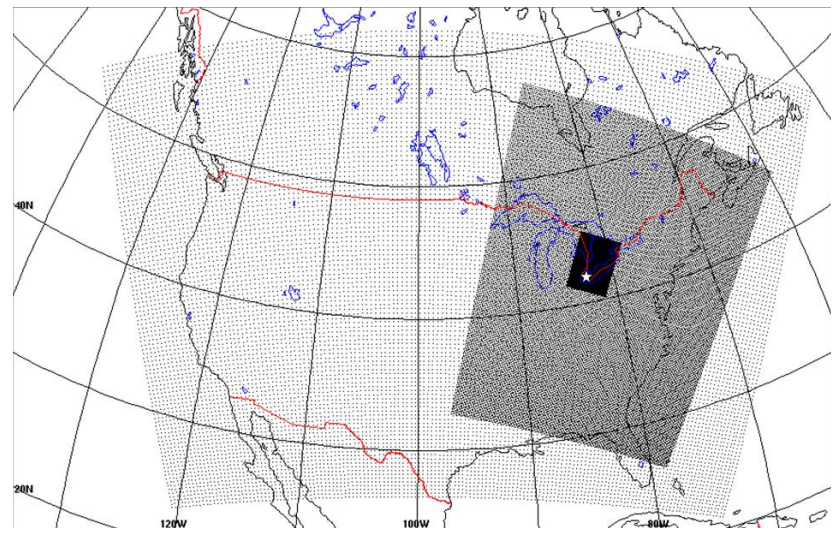

Fig. 2. AURAMS $42 \mathrm{~km}, 15 \mathrm{~km}$ and $2.5 \mathrm{~km}$ BAQS-Met domains.

resolution domain meteorological simulations (Fig. 1). The parameterizations of model physics change with resolution in GEM; convective parameterizations are required in the coarse resolution model, while these are no longer required in the explicit physics of the high resolution model. The global variable-resolution configuration of GEM was constrained by operational analyses at six hour intervals.

A three level grid nesting setup was used for the AURAMS CTM simulations: an outer, $42 \mathrm{~km}$ polarstereographic gird, which covered a North American domain $(150 \times 106$ grid points $)$ and used a 15 min time-step drove a smaller $15 \mathrm{~km}$ grid that covered an Eastern North American domain $(160 \times 210$ grid points $)$ and used a fifteen minute time-step; this second grid in turn drove a third, $2.5 \mathrm{~km}$ grid that spanned a southern Ontario domain $(157 \times 211$ grid points) and used a 2-min time-step (Fig. 2). Similar to GEM, chemistry results from the coarser resolution CTM domains were used as lateral boundary conditions for the two nested domains. Upper boundary condition methodologies were applied for all AURAMS domains.

The two GEM domains share the same vertical coordinate and layer structure, as do the three AURAMS domains. GEM uses a type of pressure coordinate; $\left(\eta=\frac{P-P_{\mathrm{T}}}{P_{\mathrm{S}}-P_{\mathrm{T}}}\right)$, where $P_{\mathrm{T}}$ is the model pressure top and $P_{\mathrm{S}}$ is the surface pressure). AURAMS uses modified Gal-Chen coordinates $\left(\varsigma=\frac{z-z_{\text {terrain }}}{z_{\text {top }}-z_{\text {terrain }}} z_{\text {top }}\right)$, where $z_{\text {terrain }}$ is the local terrain height, and $z_{\text {top }}$ is the model top. The level structure of the two models may be compared using $z_{\text {terrain }}=0, P_{\mathrm{S}}=1013.25 \mathrm{hPa}$, $P_{\mathrm{T}}=10 \mathrm{hPa}$ (Fig. 3).

\subsection{Variations on a theme: ten methodologies}

In our Base Case (original AURAMS configuration), the lateral and top boundary conditions for ozone were extracted from a global, monthly-varying gridded ozone climatology developed by Logan (1999). The US standard atmosphere was used to map ozone profiles at different locations from the pressure levels used by the climatology onto model vertical 

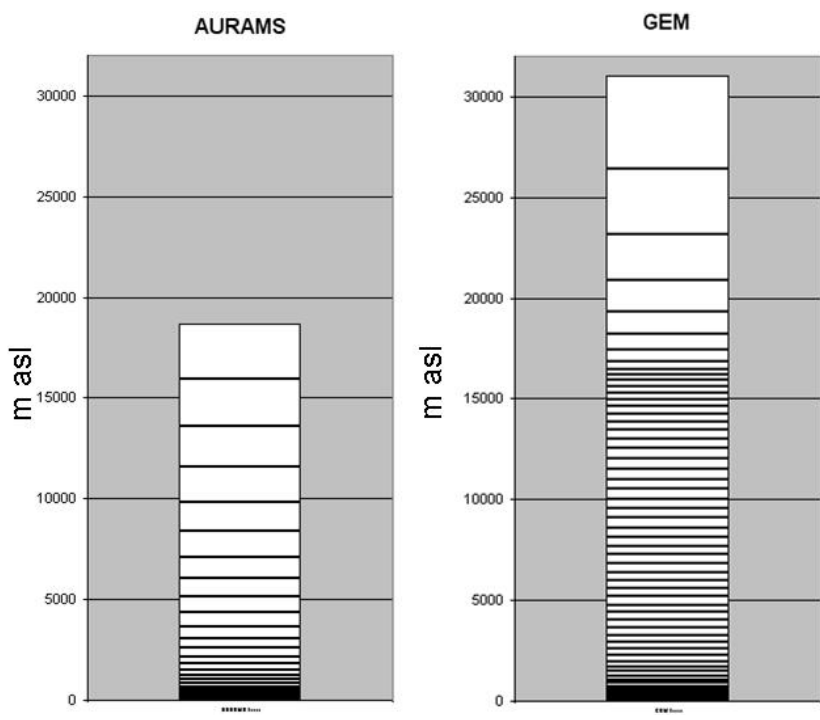

Fig. 3. Comparison of Vertical coordinate for GEM and AURAMS, plotted relative to sea-level $(1013.25 \mathrm{hPa})$.

levels; and ozone values above the $100 \mathrm{mb}$ top of the climatology were assumed to remain constant with height. The ten scenarios carried out here use same modelling structure (described above) for each simulation. The differences between the scenarios relate to four different factors:

\section{(a) Dynamic tropopause-height adjustment}

This methodology still makes use of the Logan (1999) ozone climatology in generarting boundary conditions, but the manner in which the climatology is applied differs from the standard treatment in AURAMS. The concept arises from examining an intensive series of twice-daily ozonesonde observations made in southwestern Ontario during the summer 2007 BAQS-Met field study, which suggest that the ozone profiles taken during short-lived stratosphere-troposphere exchange events differ from those representative of background conditions (He et al., 2010). During one of these events, ozone in the middle to upper troposphere may be increased by hundreds of ppbv and may be a factor of four or more higher than typical values in the upper troposphere. The climatological ozone vertical profiles that are used in most limitedarea regional air-quality models to specify boundary conditions, however, are long-term averages. At an upper tropospheric level close to the climatological tropopause level, the time average will thus include "typical" upper-tropospheric ozone concentrations (when the actual tropopause is located at or above the climatological tropopause height), stratospheric ozone concentrations when the actual tropopause is located below the height of the climatological tropopause, and occasionally stratospheric ozone concentrations resulting from stratosphere/troposphere exchange (STE) events. The average will thus be considerably altered (increased) by day-to-day variations in tropopause height and by sporadic cross-tropopause events (Thouret et al., 2006). As a consequence, the middle to upper tropospheric ozone in the climatology will in general be higher than actual middle to upper tropospheric ozone concentrations. Moreover, if the model predicts a tropopause height that is higher than the climatological one, then a stratospheric values of ozone will be applied to that part of the upper troposphere that is above the climatological tropopause. That higher ozone concentration air will then be available to be mixed downwards; in effect an artificial STE event will have been generated by the model. The use of a non-tropopause-referenced ozone climatology may thus result in positive ozone biases in the upper troposphere.

In order to test this hypothesis, a relatively simple approach was used to modify the existing boundary conditions. Four observation-based concepts were used in devising the procedure.

First, the observation was made that the height of the tropopause as indicated by temperature profiles was closely linked to the ozone profile. Both fields show rapid increases in magnitude with increasing height above the tropopause (note that the air-quality model top in this case is well below the maximum in the ozone concentrations, which occurs at greater altitudes).

Second, we noted that the inclusion of STE events will smoothed both the temperature and ozone climatology in a similar way, relative to the background profile. A comparison of the "US Standard Atmosphere" temperature profile to profiles in Logan's data showed a good correspondence: both show a relatively smooth increase in magnitude rather than the sharp transition of individual background (non-exchange event) days. The US Standard Atmosphere's tropopause height was therefore used here to represent the average tropopause height corresponding to ozone climatological data such as Logan's, over North America. The issue of smoothing of the tropopause location due to the use of coarse resolution satellite data in data assimilation has been identified as a source of error in the prediction of tropopause inversion layer strength (Birner et al., 2006), and in the creation of seasonal average ozone climatologies (Thouret et al., 2006).

Third, we note that the tropopause height may be estimated according to the revised World Meteorological Organization criterion, specifically (JPL, 2010):

1. "The first tropopause (i.e., the conventional tropopause) is defined as the lowest level at which the lapse rate decreases to $2 \mathrm{~K} \mathrm{~km}^{-1}$ or less, and the average lapse rate from this level to any level within the next higher $2 \mathrm{~km}$ does not exceed $2 \mathrm{~K} \mathrm{~km}^{-1}$ (WMO, 1966).

2. If above the first tropopause the average lapse rate between any level and all higher levels within $1 \mathrm{~km}$ exceed $3 \mathrm{~K} \mathrm{~km}^{-1}$, then a second tropopause is defined by the same criterion as under the statement above. This 
Table 1. Description of boundary condition setup used for simulations in this study.

\begin{tabular}{|c|c|}
\hline & Description \\
\hline Base Case & $\begin{array}{l}\text { Default AURAMS: includes sponge zone on the top boundary, } \\
\text { vertical wind field correction for mass consistency (OPT2), } \\
\text { fixed ozone climatology with no extrapolation of ozone values } \\
\text { for the heights above the climatology. }\end{array}$ \\
\hline Opt1 & As in the Base Case, but with no mass consistency correction. \\
\hline Opt2_dyn & $\begin{array}{l}\text { As in the Base Case, but with DYN1 dynamic ozone boundary } \\
\text { conditions }\end{array}$ \\
\hline Opt1_dyn & $\begin{array}{l}\text { No mass consistency correction, DYN1 dynamic ozone } \\
\text { boundary conditions, includes sponge zone on the top } \\
\text { boundary. }\end{array}$ \\
\hline Opt2_wosp & As in Base Case, but without the top boundary sponge zone. \\
\hline Opt2_Wosp_Extrap & $\begin{array}{l}\text { As above, but with ozone extrapolated within the model when } \\
\text { the model top exceeds the limit of the climatology. }\end{array}$ \\
\hline Opt1_Dyn_Extrap_Wosp & $\begin{array}{l}\text { No mass consistency correction, DYN1 dynamic ozone } \\
\text { climatology, ozone extrapolated within the model when the } \\
\text { model top exceeds the limit of the climatology, no sponge zone. }\end{array}$ \\
\hline Opt1_Dyn_Extrap2_Wosp & $\begin{array}{l}\text { No mass consistency correction, DYN } 2 \text { dynamic ozone } \\
\text { climatology, ozone extrapolated within the model when the } \\
\text { model top exceeds the limit of the climatology, no sponge zone. }\end{array}$ \\
\hline Opt3_Dyn_Extrap2_Wosp & $\begin{array}{l}\text { Density advection mass consistency correction, DYN2 dynamic } \\
\text { ozone climatology, ozone extrapolated within the model when } \\
\text { the model top exceeds the limit of the climatology, no sponge } \\
\text { zone. }\end{array}$ \\
\hline Opt4_Dyn_Extrap2_Wosp & $\begin{array}{l}\text { Density*Jacobian advection mass consistency correction, } \\
\text { DYN2 dynamic ozone climatology, ozone extrapolated within } \\
\text { the model when the model top exceeds the limit of the } \\
\text { climatology, no sponge zone. }\end{array}$ \\
\hline
\end{tabular}

tropopause may be either within or above the $1 \mathrm{~km}$ layer (Roe and Jasperson, 1980).

3. A level otherwise satisfying the above definition of tropopause, but occuring at an altitude below that of the $500 \mathrm{mb}$ level, will not be designated a tropopause unless it is the only level satisfying the definition and the average lapse rate fails to exceed $3 \mathrm{~K} \mathrm{~km}^{-1}$ over at least $1 \mathrm{~km}$ in any higher layer (Roe and Jasperson, 1980).”

Fourth and last, we noted that vertically stretching or shrinking the climatological ozone vertical profile by the ratio of tropopause heights (model-generated to US Standard atmosphere), resulted in climatological ozone profiles that were much closer in appearance to the observed profiles in the model domain.

Two different approaches were taken to make use of these observation-based concepts: in the first, the ratio of the tropopause height locations (time-varying model to
US Standard Atmosphere) was used to linearly scale all ozone climatology heights ("dynamic" scaling: DYN1, see Table 1), prior to their application on the lateral and top model boundaries. In the second, the surface, the tropopause height, and the height of the top of the climatology were used to create two regions of linear interpolation, above and below the tropopause respectively, to scale the heights of the ozone climatology (DYN2, see Table 1). Both of these approaches dynamically shift the location of the ozone climatological fields in the vertical, prior to their use as model boundary conditions at any given time step.

\section{(b) Extrapolation of the available ozone climatology to (or beyond) the model top}

The default AURAMS 1.4.0 makes use of the static ozone climatology of Logan (1999), the top layer of which is at $100 \mathrm{mb}$. This climatological top level was often below the modified Gal-Chen coordinate AURAMS top of $18 \mathrm{~km}$ : by 
default, AURAMS would use the uppermost climatological ozone value for all grid points above the $100 \mathrm{mb}$ region. The (Extrap) and (Extrap2) methodologies extrapolate from the existing climatology above that level, either internally to the model at every gridpoint requiring extrapolation (Extrap), or using a pre-processing step of extrapolating all climatological ozone values to $50 \mathrm{mb}$ (well above the AURAMS model top, then interpolating within the resulting 50 to $100 \mathrm{mb}$ region within the model, Extrap2). Both methodologies attempt to make the model's use of the upper portion of the available climatology more realistic (since the ozone profile is known to continue increasing above $100 \mathrm{mb}$ ); a better, longer-term solution would be to generate new climatology from available data, that always extends above the AURAMS top.

\section{(c) The use or absence of a sponge zone at the model lid}

Sponge zones are sometimes employed to smooth the transported field in the vicinity of a static boundary condition, to prevent spatial discontinuities between the boundary condition and the time-dependent fields from resulting in errors (e.g. from over- and under-shooting in Semi-Lagrangian advection). However, the use of a sponge zone in a region with a large gradient in concentration (as is the case for ozone, at the model top) may de facto increase the transport of upper boundary ozone into the model domain. The sponge zone blending will add additional mass to the inner grid points, in addition to that from advection, when the latter is transporting mass into the model domain. The default setting of AURAMS 1.4.0 was to use a three-grid point sponge zone at the model top: the top layer set by climatology, the next layer down being a parametric cosine blend of the last time-step's forecast and the climatology, and the 3rd layer down being completely determined by the forecast. The very coarse vertical resolution near the top of the model $(\sim 3 \mathrm{~km})$ implies that errors of this nature associated with the sponge zone may be substantial. One set of tests (Wosp; "without sponge") evaluates the effect of removing this sponge zone.

\section{(d) The choice of mass consistency correction methodology}

The meteorological model does not formally conserve air density in its prognostic equations, and interpolation errors in the wind fields resulting from interpolation between meteorological model and air-pollution model grids will also occur. The consistency between wind fields and air density may be reduced by these considerations; previous work (Byun, 1999a,b; Odman and Russell, 2000; Lee et al., 2004; Hu et al., 2006) has shown that correcting for these effects improves the accuracy of air-quality forecasts. To examine the potential impact of mass consistency corrections on the transported chemical species, three different methodologies will be considered here: (1) The wind fields may be corrected
- that is, the error in mass consistency is assumed to reside in one or more of the components of the 3-D winds, and corrections to the wind field are applied in order to reduce this error (Yamartino, 1993; Byun, 1999a,b). (2) The errors in mass consistency are assumed to be reflected by errors in air density: the ratio of the meteorological model's diagnostically predicted air density to the air density that resulting from advection from the previous time step, is used to correct the advected tracers. (3) The errors in mass consistency are assumed to be reflected by errors in both air density and the vertical coordinate Jacobian transformation: the ratio of the advected product of the Jacobian and density to the diagnostically predicted product of the Jacobian and density is used to correct the advected product of the Jacobian and the tracer of interest. Four different approaches were thus compared here: no mass consistency correction (Opt1), a vertical wind field correction (Opt2; Byun, 1999b), an air density advection and ratio correction (Opt3; Chang et al., 1997), and a product of air density with Jacobian advection and ratio correction (Opt4; Byun, 1999b). Byun (1999b) refers to the Opt3 approach as "an ad hoc empirical method", "presented without theoretical explanation"; we have included it here out of completeness sake, and since it has been used in past air-quality models (Chang et al., 1997).

The order of application of the mass consistency and mass conservation in AURAMS is of importance with regards to the use of mass consistency algorithms. If the Opt2 strategy is used, this correction takes place prior to the application of AURAMS' semi-Lagrangian advection algorithm. If the Opt 3 or Opt 4 strategies are used, the advection of air density or (air density $\times$ Jacobian), and the calculation of the correction terms, are carried out prior to the advection of these quantities, and the mass consistency corrections are applied after the subsequent tracer advection takes place. A final stage of the processing is a global mass conservation correction, which is applied after all mass consistency corrections have been applied (Gong et al., 2003; Priestly, 1993).

Combinations of the above methodologies $(a-d)$ could lead to many different approaches for making use of climatological boundary conditions. Processing-time constraints led us to examine a sub-set here. Our tests thus represent improvements and additions along a particular line of enquiry rather than an exhaustive examination of all possible combinations. Table 1 describes the individual scenarios, and gives their designators used in subsequent analysis.

Each methodology was used in a separate 2.5 month scenario simulation (subsequent to two weeks spin-up) for the BAQS-Met $42 \mathrm{~km}$ domain (Fig. 2). The results were compared using standard statistics to surface observations from the AIRNow network, and to ozonesondes released at the BAQS-Met study's Harrow site $\left(42.03^{\circ} \mathrm{N}, 82.9^{\circ} \mathrm{W}\right)$. The base case, and the methodology deemed to have the best overall performance, were then used for $15 \mathrm{~km}$ and $2.5 \mathrm{~km}$ BAQS-Met simulations (only the latter will be discussed here), and for a separate set of simulations at 36 and $12 \mathrm{~km}$ 
grid spacing along a domain in western Canada. The latter shows the effects of the choice of boundary conditions on ozone originating from exchange events and the importance of the coupling between boundary layer and free troposphere on the forecasted ozone concentration.

\section{Model performance evaluation}

\subsection{North American domain: $42 \mathrm{~km}$ grid BAQS-Met simulations compared to AIRNow}

AIRNow data between 3 June 2007 and 31 August 2007 were used to evaluate each of the model scenarios described above, for the largest domain shown in Fig. 2. The mean bias (MB), normalized mean bias (NMB), correlation coefficient $(R)$, and root-mean-square-error (RMSE) were calculated for the daily 1-h maximum, daily mean, and hourly (all values) of both ozone and $\mathrm{PM}_{2.5}$, with the results given in Tables 2 and 3, respectively.

The ozone results (Table 2) show that all methodologies have a positive $\mathrm{MB}$ and $\mathrm{NMB}$, for all three ozone metrics evaluated.

The original model setup, Base Case (Table 1), has the highest MB, NMB and RMSE of all methodologies. The Base Case also has the highest correlation coefficient for the daily $1 \mathrm{~h}$ maximum and daily mean, though the variation in correlation coefficients between the different methodologies is usually small.

The simulation with the best overall performance (based on these surface observations alone) is Opt2_Wosp_Extrap; incorporating a vertical velocity wind-field mass consistency correction, no sponge zone at the model top, and climatological ozone concentrations extrapolated in instances where the model top is above the top of the climatology. This simulation has the lowest magnitude MB, NMB and RMSE, without a significant decrease in $R$ compared to the base case (for hourly ozone, this simulation has the highest $R$ score).

A second group of methodologies (Opt1_Dyn, Opt2_Wosp, Opt1_Dyn_Extrap_Wosp, and Opt1_Dyn_Extrap2_Wosp)

have similar overall performance, worse than

Opt2_Wosp_Extrap, but better than the other scenarios and the Base Case. These scenarios still show a significant improvement in the MB, NMB, RMSE relative to the base case, again with relatively little change in the correlation coefficient.

A final group of methodologies (Opt1, Opt2_Dyn, Opt3_Dyn_Extrap2_Wosp, Opt4_Dyn_Extrap2_Wosp) also have similar overall performance, and are the closest to the relatively poor performance of the original Base Case.

Comparing the above statistics, a few observations may be made:

1. The incorporation of dynamic tropopause improves the model prediction at the surface;
Table 2. Evaluation statistics for $42 \mathrm{~km}$ grid simulations for Ozone. MB: mean bias, NMB: normalized mean bias, $R$ : correlation coefficient, RMSE: Root Mean Square Error. 1167 stations.

\begin{tabular}{|c|c|c|c|c|}
\hline \multirow[b]{2}{*}{ Simulation } & \multicolumn{4}{|c|}{ Daily $1 \mathrm{~h}$ maximum $\mathrm{O}_{3}$} \\
\hline & MB & NMB & $R$ & RMSE \\
\hline Base Case & 15.0 & 0.28 & 0.48 & 22.8 \\
\hline Opt1 & 10.2 & 0.19 & 0.47 & 20.0 \\
\hline Opt2_Dyn & 12.3 & 0.23 & 0.47 & 21.5 \\
\hline Opt1_Dyn & 8.9 & 0.17 & 0.46 & 19.7 \\
\hline Opt2_Wosp & 8.8 & 0.16 & 0.47 & 20.0 \\
\hline Opt2_Wosp_Extrap & 6.5 & 0.12 & 0.46 & 19.5 \\
\hline Opt1_Dyn_Extrap_Wosp & 8.4 & 0.16 & 0.46 & 19.5 \\
\hline Opt1_Dyn_Extrap2_Wosp & 8.6 & 0.16 & 0.46 & 19.5 \\
\hline Opt3_Dyn_Extrap2_Wosp & 11.6 & 0.22 & 0.41 & 22.1 \\
\hline \multirow[t]{2}{*}{ Opt4_Dyn_Extrap2_Wosp } & 11.6 & 0.22 & 0.38 & 22.6 \\
\hline & \multicolumn{4}{|c|}{ Daily mean $\mathrm{O}_{3}$} \\
\hline Simulation & MB & NMB & $R$ & RMSE \\
\hline Base Case & 16.0 & 0.53 & 0.45 & 19.8 \\
\hline Opt1 & 12.4 & 0.42 & 0.44 & 16.8 \\
\hline Opt2_Dyn & 13.5 & 0.45 & 0.44 & 17.9 \\
\hline Opt1_Dyn & 11.3 & 0.39 & 0.43 & 16.1 \\
\hline Opt2_Wosp & 10.4 & 0.35 & 0.43 & 15.8 \\
\hline Opt2_Wosp_Extrap & 8.0 & 0.28 & 0.43 & 14.4 \\
\hline Opt1_Dyn_Extrap_Wosp & 10.8 & 0.37 & 0.43 & 15.8 \\
\hline Opt1_Dyn_Extrap2_Wosp & 11.0 & 0.38 & 0.43 & 15.9 \\
\hline Opt3_Dyn_Extrap2_Wosp & 13.5 & 0.45 & 0.40 & 18.3 \\
\hline \multirow[t]{2}{*}{ Opt4_Dyn_Extrap2_Wosp } & 13.4 & 0.45 & 0.37 & 18.7 \\
\hline & \multicolumn{4}{|c|}{ Hourly $\mathrm{O}_{3}$ (all values) } \\
\hline Simulation & MB & NMB & $R$ & RMSE \\
\hline Base Case & 15.7 & 0.51 & 0.61 & 23.8 \\
\hline Opt1 & 12.2 & 0.41 & 0.61 & 21.2 \\
\hline Opt2_Dyn & 13.4 & 0.45 & 0.61 & 22.4 \\
\hline Opt1_Dyn & 11.0 & 0.37 & 0.61 & 20.6 \\
\hline Opt2_Wosp & 10.2 & 0.34 & 0.61 & 20.5 \\
\hline Opt2_Wosp_Extrap & 7.8 & 0.27 & 0.62 & 19.4 \\
\hline Opt1_Dyn_Extrap_Wosp & 10.6 & 0.36 & 0.60 & 20.5 \\
\hline Opt1_Dyn_Extrap2_Wosp & 10.7 & 0.36 & 0.61 & 20.5 \\
\hline Opt3_Dyn_Extrap2_Wosp & 13.2 & 0.44 & 0.57 & 22.7 \\
\hline Opt4_Dyn_Extrap2_Wosp & 13.2 & 0.44 & 0.56 & 23.0 \\
\hline
\end{tabular}

2. Removing the sponge zone also helps to reduce the positive ozone bias at the surface;

3. Extrapolating $\mathrm{O}_{3}$ climatology beyond $100 \mathrm{mb}$ (as opposed to simple extension), helps reduce the model bias at the surface, and there is a small but significant difference between the two different extrapolation methodologies;

4. Removal of the mass consistency adjustment (regardless of type) reduces the positive bias at the surface. 
Table 3. Evaluation statistics for $42 \mathrm{~km}$ grid simulations for $\mathrm{PM}_{2.5}$. MB: mean bias, NMB: normalized mean bias, $R$ : correlation coefficient, RMSE: Root Mean Square Error. 1167 stations.

\begin{tabular}{|c|c|c|c|c|}
\hline \multirow[b]{2}{*}{ Simulation } & \multicolumn{4}{|c|}{ Daily $1 \mathrm{~h}$ maximum $\mathrm{PM}_{2.5}$} \\
\hline & MB & NMB & $R$ & RMSE \\
\hline Base Case & -4.86 & -0.151 & 0.256 & 17.4 \\
\hline Opt1 & -5.58 & -0.190 & 0.249 & 17.4 \\
\hline Opt2_Dyn & -4.75 & -0.145 & 0.253 & 17.5 \\
\hline Opt1_Dyn & -5.43 & -0.181 & 0.248 & 17.5 \\
\hline Opt2_Wosp & -5.26 & -0.172 & 0.256 & 17.4 \\
\hline Opt2_Wosp_Extrap & -5.39 & -0.178 & 0.257 & 17.4 \\
\hline Opt1_Dyn_Extrap_Wosp & -5.46 & -0.183 & 0.248 & 17.5 \\
\hline Opt1_Dyn_Extrap2_Wosp & -5.45 & -0.182 & 0.248 & 17.5 \\
\hline Opt3_Dyn_Extrap2_Wosp & -4.76 & -0.152 & 0.256 & 17.3 \\
\hline \multirow[t]{2}{*}{ Opt4_Dyn_Extrap2_Wosp } & -4.69 & -0.149 & 0.254 & 17.3 \\
\hline & \multicolumn{4}{|c|}{ Daily mean $\mathrm{PM}_{2.5}$} \\
\hline Simulation & MB & NMB & $R$ & RMSE \\
\hline Base Case & -1.00 & -0.010 & 0.361 & 8.1 \\
\hline Opt1 & -1.47 & -0.058 & 0.354 & 8.0 \\
\hline Opt2_Dyn & -0.86 & 0.004 & 0.357 & 8.2 \\
\hline Opt1_Dyn & -1.32 & -0.043 & 0.354 & 8.1 \\
\hline Opt2_Wosp & -1.15 & -0.024 & 0.360 & 8.1 \\
\hline Opt2_Wosp_Extrap & -1.19 & -0.029 & 0.361 & 8.1 \\
\hline Opt1_Dyn_Extrap_Wosp & -1.33 & -0.044 & 0.354 & 8.1 \\
\hline Opt1_Dyn_Extrap2_Wosp & -1.33 & -0.044 & 0.354 & 8.1 \\
\hline Opt3_Dyn_Extrap2_Wosp & -0.86 & -0.008 & 0.364 & 8.0 \\
\hline \multirow[t]{3}{*}{ Opt4_Dyn_Extrap2_Wosp } & -0.82 & -0.004 & 0.361 & 8.1 \\
\hline & \multicolumn{4}{|c|}{ Hourly $\mathrm{PM}_{2.5}$ (all values) } \\
\hline & MB & NMB & $R$ & RMSE \\
\hline Base Case & -0.79 & 0.014 & 0.296 & 10.7 \\
\hline Opt1 & -1.27 & -0.036 & 0.293 & 10.6 \\
\hline Opt2_Dyn & -0.18 & 0.076 & 0.242 & 11.8 \\
\hline Opt1_Dyn & -1.13 & -0.022 & 0.293 & 10.6 \\
\hline Opt2_Wosp & -0.50 & 0.042 & 0.254 & 11.6 \\
\hline Opt2_Wosp_Extrap & -0.99 & -0.006 & 0.299 & 10.6 \\
\hline Opt1_Dyn_Extrap_Wosp & -0.69 & 0.023 & 0.250 & 11.4 \\
\hline Opt1_Dyn_Extrap2_Wosp & -1.13 & -0.023 & 0.294 & 10.6 \\
\hline Opt3_Dyn_Extrap2_Wosp & -0.67 & 0.013 & 0.299 & 10.7 \\
\hline Opt4_Dyn_Extrap2_Wosp & -0.63 & 0.018 & 0.299 & 10.7 \\
\hline
\end{tabular}

The corresponding scores for $\mathrm{PM}_{2.5}$ are shown in Table 3. The changes to the $\mathrm{PM}_{2.5}$ are relatively small compared to ozone (compare NMB columns, Tables 2 and 3); the changes in methodology have a much larger impact on ozone forecast accuracy, than on that of particulate matter.

If the analysis of surface sites alone is used to evaluate the model methodologies, the Opt2_Wosp_Extrap methodology has the best performance, and results in the greatest improvement in MB, NMB and RMSE compared to the other scenarios. However, subsequent comparisons to ozonesondes (discussed below) show that this improved performance at the surface comes at the expense of greatly reduced performance
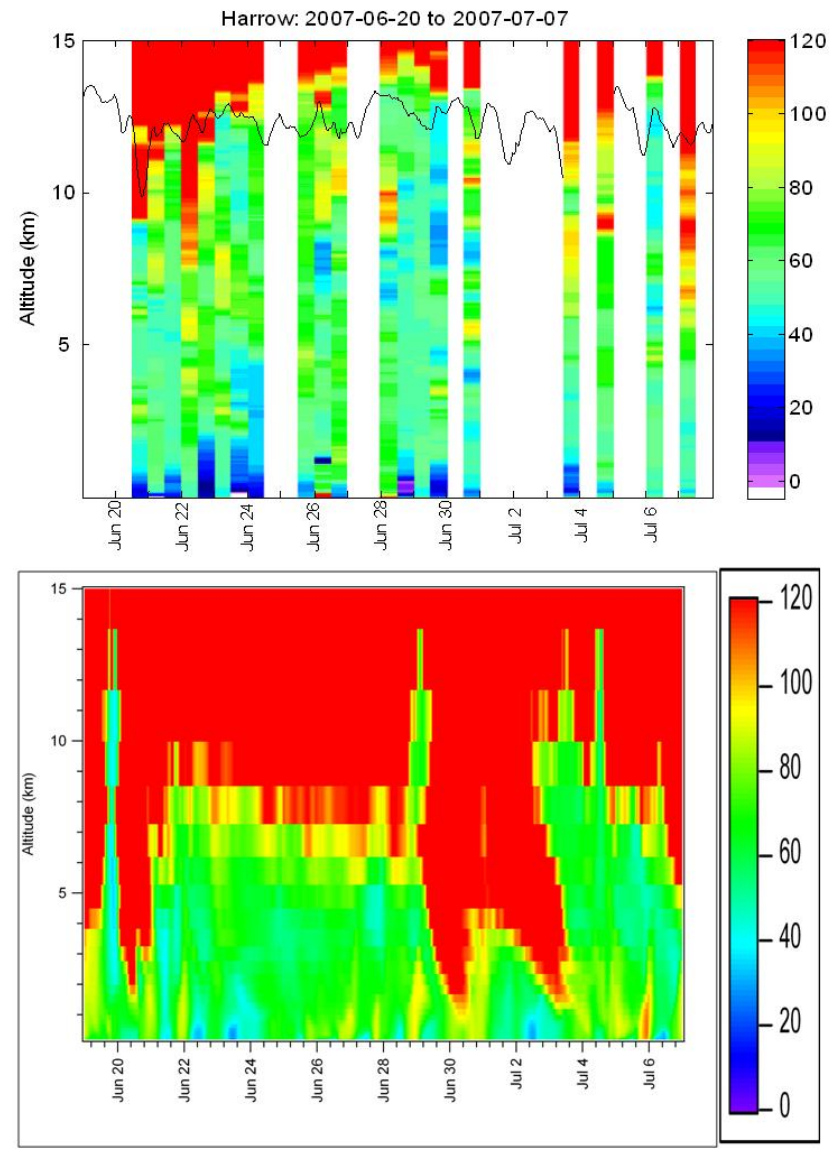

Fig. 4. Comparison of ozone from (a) observations (ozonesondes) and (b) 42 km AURAMS Base Case, BAQS-Met Intensive, Harrow site.

in the mid-to-upper troposphere, precluding its use in subsequent analysis.

\subsection{North American domain: $42 \mathrm{~km}$ grid BAQS-Met simulations compared to Harrow ozonesondes}

Twice daily ozonesonde measurements were carried out at the Harrow BAQS-Met site. A comparison between the Base Case ozone and the observations is shown in Fig. 4. The most striking feature about the comparison is the extent to which the model ozone is biased high in the free and upper troposphere. In the observations (Fig. 4a), ozone in the region between 3 and $10 \mathrm{~km}$ is rarely greater than $80 \mathrm{ppbv}$, while the Base Case values (Fig. 4b) are often greater than $120 \mathrm{ppbv}$, especially above $7 \mathrm{~km}$. The observations show the presence of high concentration ozone resulting from troposphere/stratospheric exchange (He et al., 2010) - similar events are depicted in the Base Case simulation, but are much stronger than in the observations, resulting in $>120 \mathrm{ppbv}$ being brought down to within $2 \mathrm{~km}$ of the surface, rather than 

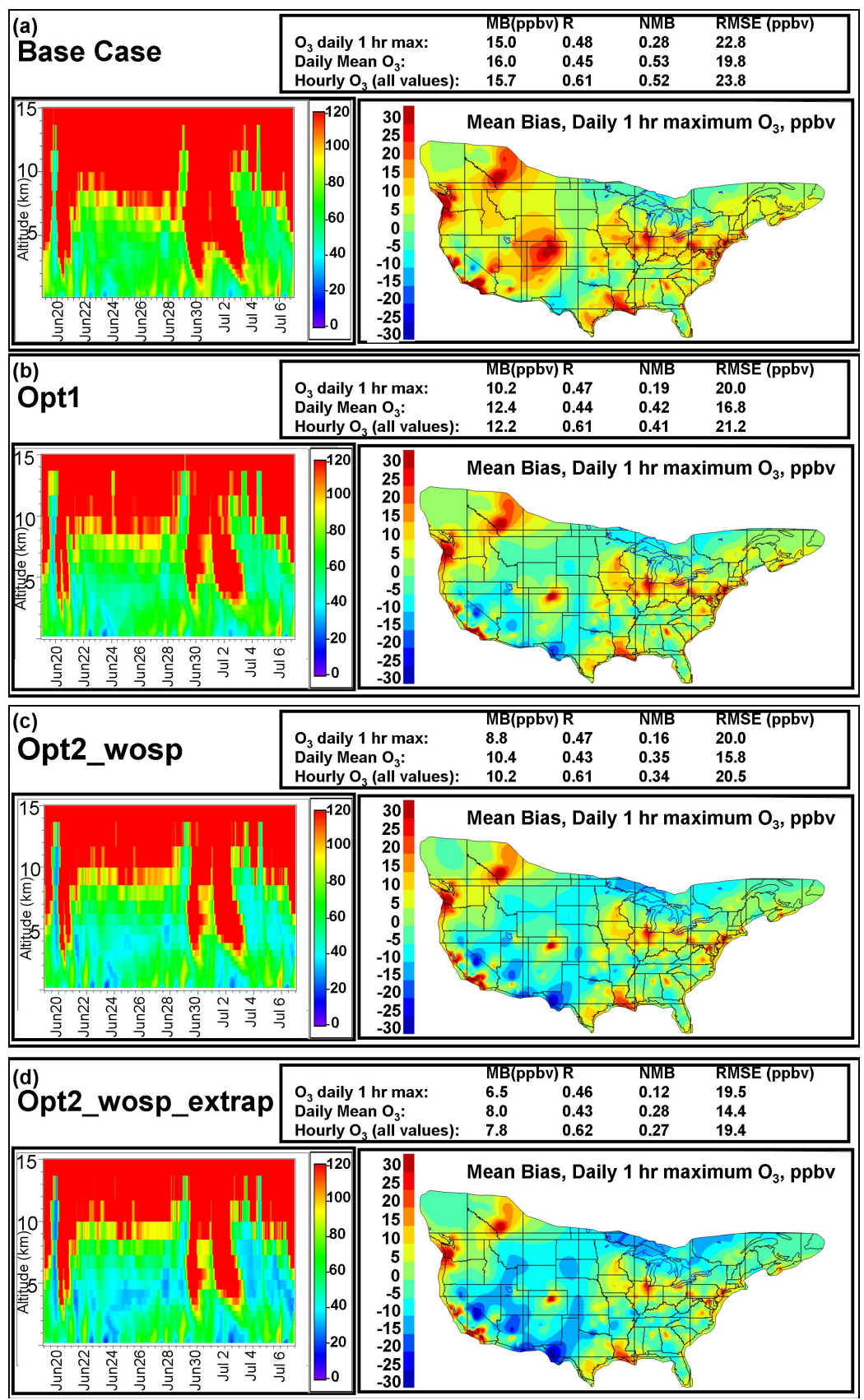

Fig. 5. (a) and (b): Model-derived ozone profiles for comparison to ozonesondes(left), $42 \mathrm{~km}$ domain statistics (upper right), and kriged mean bias of surface maximum daily ozone (lower right), for Base Case and Opt1 methodologies, 3 June-31 August 2007. (c) and (d): As in (a) and (b), but for Opt2_wosp and Opt2_wosp_extrap methododologies.

the 7 to $8 \mathrm{~km}$ lower reach of these intrusions depicted in the observations. The Base Case scenario is clearly biased high throughout the ozone profile, not just at the surface as suggested by Table 2 .

Figure 5 compares model-generated ozone profiles at Harrow, the surface network mean biases of the daily $1 \mathrm{~h}$ maximum ozone, and the ozone statistics, for each of the methodologies considered here. The surface network mean biases have been contoured using kriging in order to better show the spatial pattern, and a mask has been applied to show only the part of the domain containing station data. These figures show that the surface performance (images on the right-hand-side of Fig. 5 and in the summary statistics of Table 2) is sometimes at odds with the performance throughout the profile (images on the left-hand-side of Fig. 5). The Base Case, and all of the methodologies that do not make 

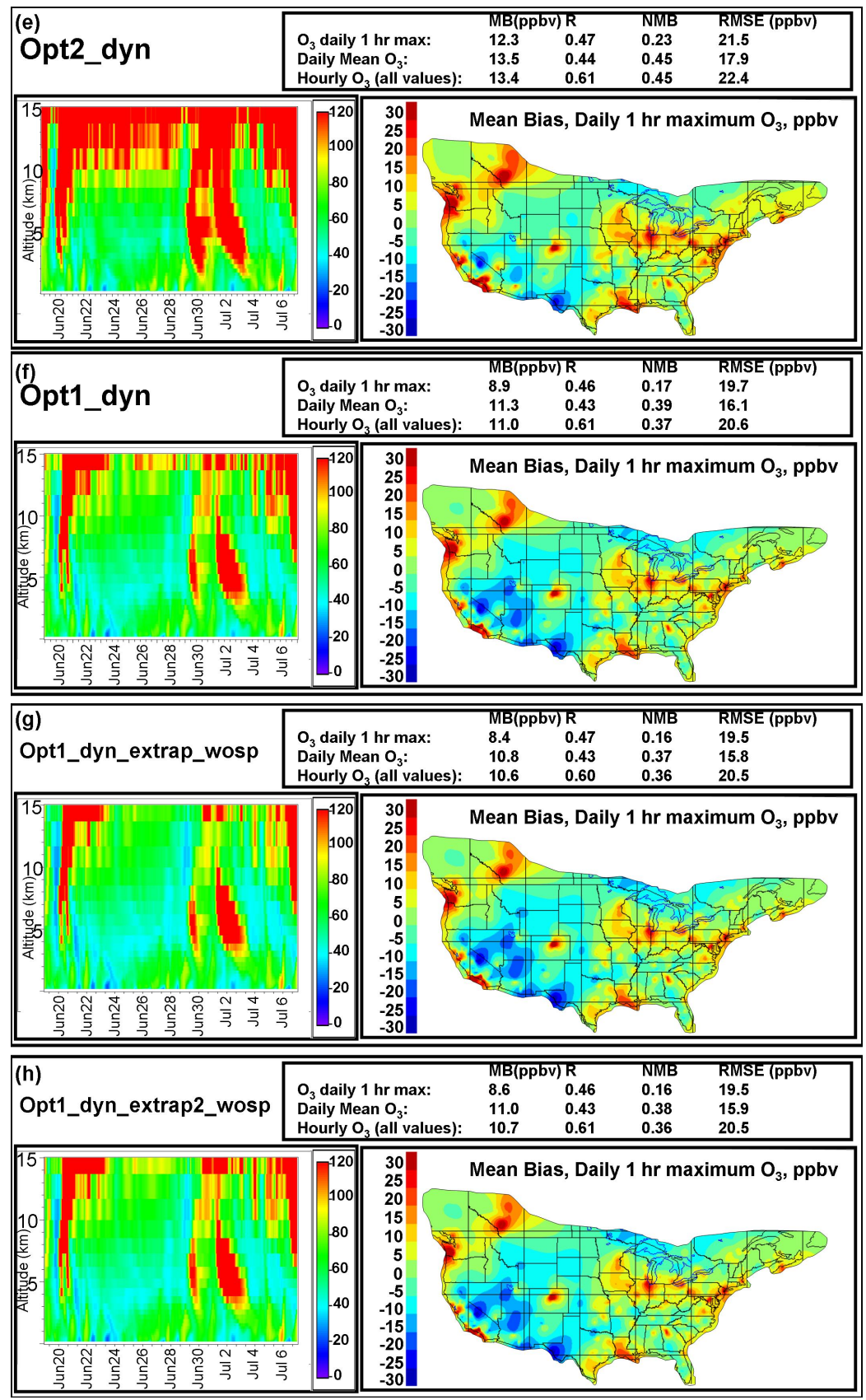

Fig. 5. (e) and (f): As in (a) and (b), but for Opt2_dyn and Opt1_dyn methodologies. (g) and (h) As in (a) and (b), but for Opt1_dyn_extrap_wosp and Opt1_dyn_extrap2_wosp methodologies.

use of some form of dynamic ozone climatology (Fig. 5ad; Base Case, Opt1, Opt2_Wosp, Opt2_Wosp_Extrap, Opt2) all significantly overestimate the ozone concentrations in the model profile.

The response at the surface (right-hand surface maps, Fig. 5) is varied between the different simulations. For example, the "Opt2_Wosp_Extrap" simulation, which had the best overall statistical scores from the above analysis (Fig. 5d), has achieved that end through the creation of negative mean bias values in much of the domain, while still being biased high through much of the middle to upper troposphere (compare simulated ozone profiles, Fig. 5d, to observations, Fig. 4a). With the exception of the "density advection" and "density*Jacobian" simulations (Fig. 5i and j, respectively), those simulations employing some form of dynamic ozone climatology adjustment have more realistic ozone profiles (Fig. 5e-h). Those with the closest appearance to the measured ozone profile 


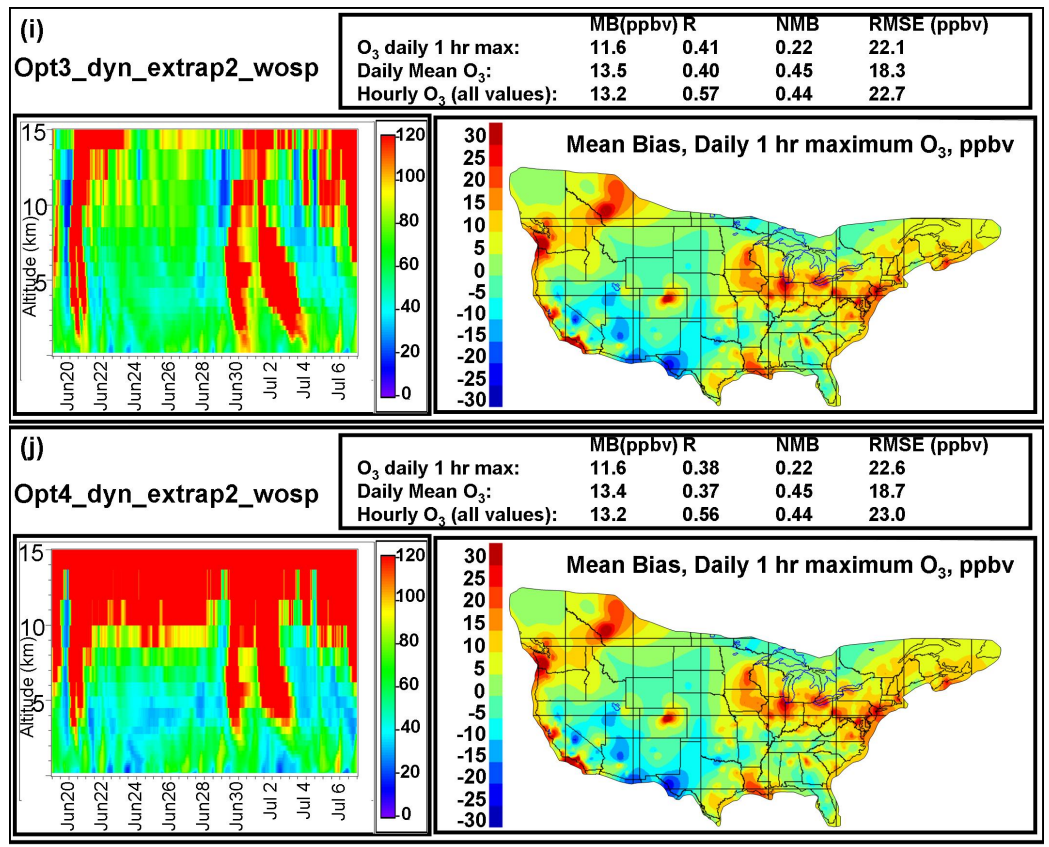

Fig. 5. (i) and (j) As in (a) and (b), but for Opt3_dyn_extrap2_wosp and Opt4_dyn_extrap2_wosp methodologies.

are Opt1_dyn, and Opt1_Dyn_Extrap2_Wosp. Of these, Opt1_Dyn_Extrap2_Wosp has the better surface performance, from the statistics of Table 2.

Comparing different simulations in Fig. 5 allows further analysis of the different methodologies. For example, comparing the simulated ozone profiles of Fig. 5a and b: an undesired result of the use of the vertical velocity mass consistency is an increase in the downward transport of ozone: ozone concentrations are higher at any given altitude in the Base Case (Fig. 5a) than in the mass-consistency-less Opt1 scenario (Fig. 5b). Similarly, comparing Fig. 5a with Fig. 5c shows that the use of a top layer sponge zone results in excessive downward ozone transport, regardless of whether or not extrapolation of the ozone climatology is employed (Fig. 5d). A substantial improvement over the Base Case profile values results from the incorporation of a dynamic ozone climatology methodology (compare Fig. 5a with Fig. 5e, or Fig. $5 f$ with Fig. 5b), though high concentration ozone is still mixed down to the surface. If the mass consistency correction on the vertical velocities is then removed, an ozone profile similar to the observations results (compare Fig. 5e and f). Figure $5 \mathrm{~g}$ and $h$ are variations on this latter theme; no mass consistency correction, but without the top sponge zone, with different methods of doing the extrapolation, resulting in only minor changes to both profiles and surface statistics. Mass consistency is again explored in Fig. $5 \mathrm{i}$ and j. Here, the density and density*Jacobian advection methodologies were applied, but these reduce the overall accuracy of the results; high ozone concentrations are again brought down from upper levels. Note that these two different approaches resulted in similar surface statistics, yet very different ozone profiles in the upper Troposphere.

Time-specific ozone profiles are examined in more detail in Figs. 6 and 7, which show the observed ozone (diamond symbols) and the simulated ozone from each of the different methodologies, throughout the entire modelled profile $(a, b)$ and in the lowest $2 \mathrm{~km}$ of the atmosphere (c,d). Figure 6 shows the behaviour when the ozone is perturbed by a stratospheric exchange event, while Fig. 7 depicts the more typical behaviour in the absence of intrusions. Figures $6 \mathrm{a}$ and $7 \mathrm{a}$ show that the best surface-performance scenario (Opt2_Wosp_Extrap) is biased very high above $6 \mathrm{~km}$ altitude. The methodologies with the best fit to the observations up to $12 \mathrm{~km}$ all incorporate dynamic ozone climatology (Figs. 6 and 7a,b). Figures 6 and 7 (c,d) show that the choice of boundary condition methodologies has a strong impact on the model results close to the surface; the shape of the simulated profiles and their proximity to the observations vary by $20 \mathrm{ppbv}$ when the profile is perturbed by the exchange event (Fig. 6c,d), and 12 ppbv under more "normal" conditions (Fig. 7c,d). The simulation with the best fit at the surface (Opt2_Wosp_Extrap, here, Figs. 6c and 7c), tends to be biased high in the middle to upper troposphere.

We suspect that the improved surface performance for the Opt2 methdologies may be due to compensating errors in the advection algorithm. The very large upper to middle troposphere concentration gradient introduced by the use of the Opt 2 methodology results in vertical advection undershooting in the semi-Lagrangian advection's interpolation near the surface, hence driving the overall surface ozone 
(a) Ridgetown Ozonesonde, 00:40Z, June 21, 2007

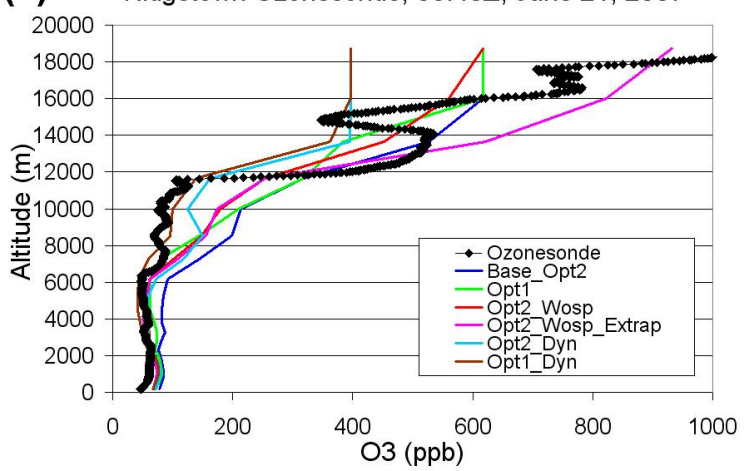

(b) Ridgetown Ozonesonde, 00:40Z, June 21, 2007

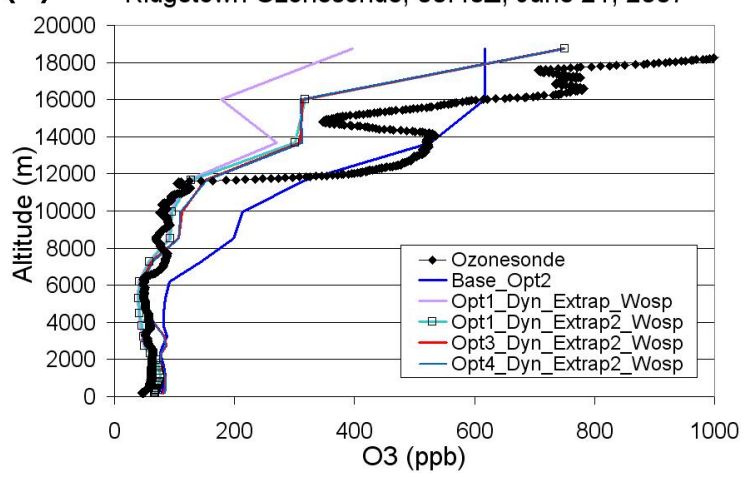

(c) Ridgetown Ozonesonde, 00:40Z, June 21, 2007

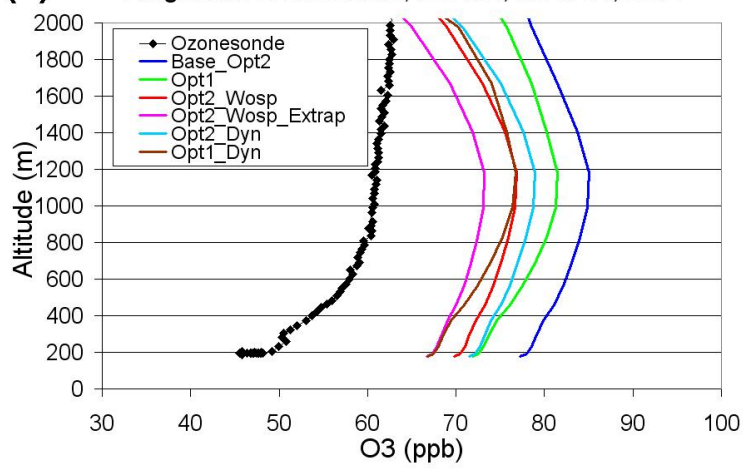

(d) Ridgetown Ozonesonde, 00:40Z, June 21, 2007

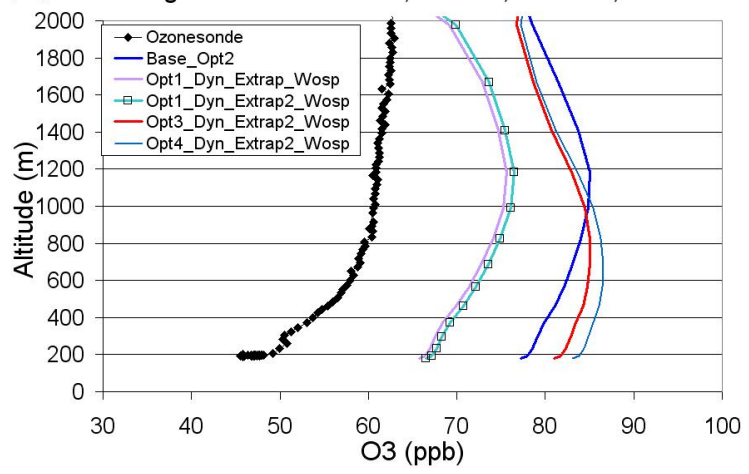

Fig. 6. (a) and (b) Comparison between observed ozone profile and $12 \mathrm{~km}$ grid simulations, 00:40Z, 21 June 2007. (a) Entire model vertical domain, first five scenarios; (b) Entire model vertical domain, second five scenarios. (c) and (d): As in (a) and (b), lowest $2 \mathrm{~km}$ of the atmosphere.

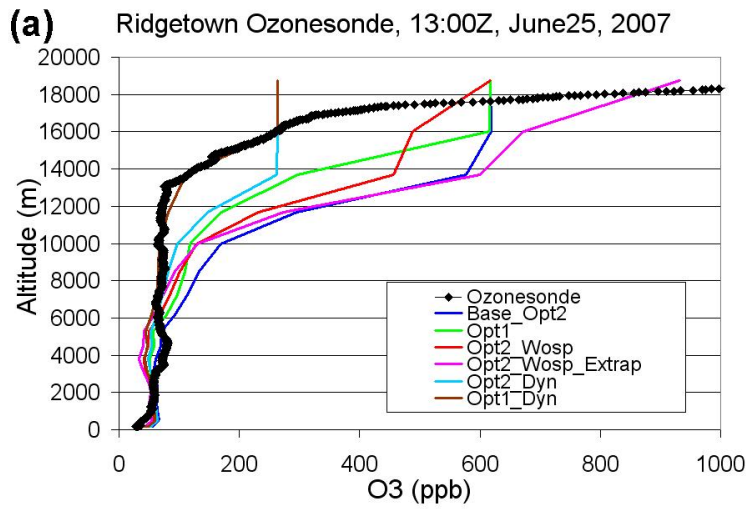

(b)

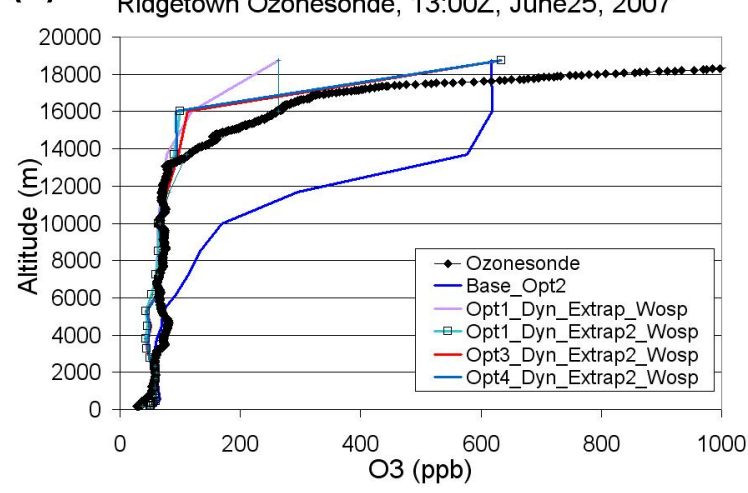

(c) Ridgetown Ozonesonde, 13:00Z, June25, 2007

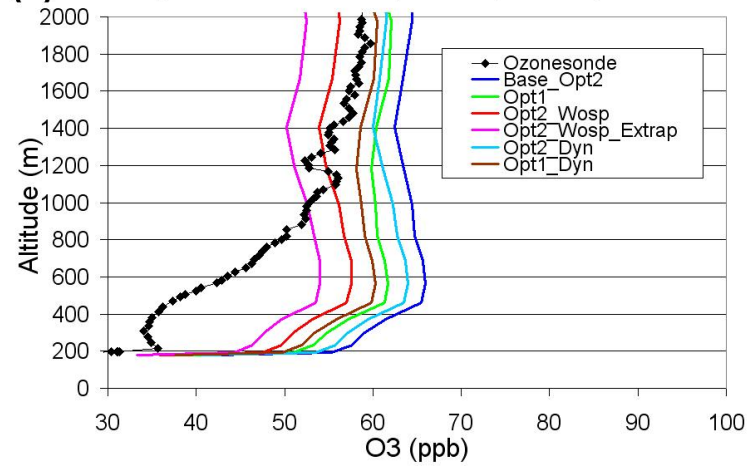

(d) Ridgetown Ozonesonde, 13:00Z, June25, 2007

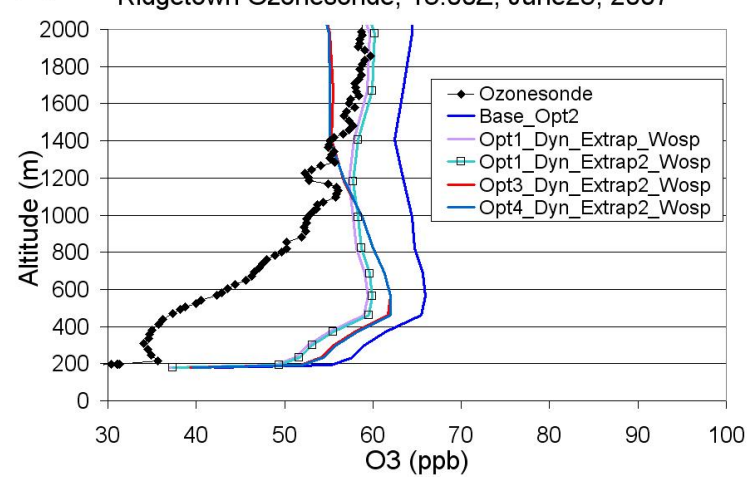

Fig. 7. (a) and (b): Comparison between observed ozone profile and $12 \mathrm{~km}$ grid simulations, 13:00 Z, 25 June 2007. (a) Entire model vertical domain, first five scenarios. (b) Entire model vertical domain, second five scenarios. (c) and (d) As in (a) and (b), lowest $2 \mathrm{~km}$ of the atmosphere. 


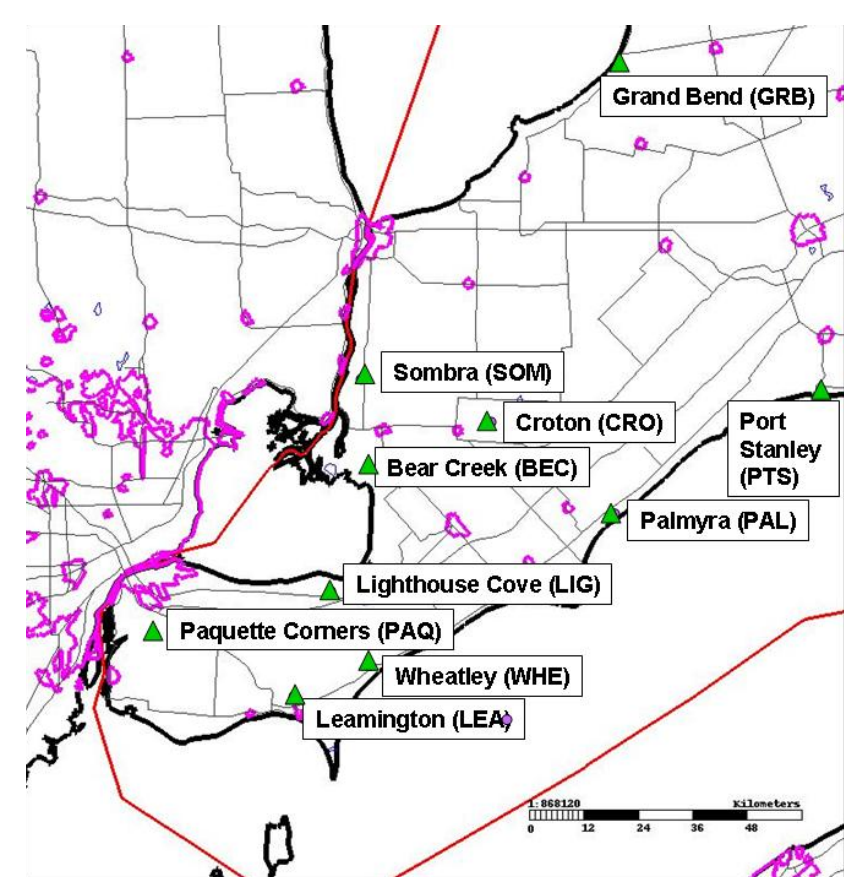

Fig. 8. Locations of BAQS-Met mesonet stations and the Harrow ozonesonde release site.

concentrations downwards. The Opt 2 methodologies tend to accumulate errors with increasing distance from the surface (the mass consistency discretization is applied first at the surface, and then at increasingly higher layers in the atmosphere). The Opt2, Opt3, and Opt4 methodologies all result in significant positive biases in ozone in the middle to upper troposphere in our modelling system. Our high resolution tests therefore do not make use of these methodologies.

\section{Case study 1: AURAMS high resolution simulations compared to BAQS-Met Mesonet surface observations}

This case study examines the impact of improved model forecasts at coarse resolution (transferred to the high resolution domain as lateral boundary conditions) on the model forecast at the nested higher resolution, as well as that of the top boundary condition, applied at all resolutions. The Base Case and Opt1_Dyn_Extrap2_Wosp $42 \mathrm{~km}$ simulations were used to provide the lateral boundary conditions for $15 \mathrm{~km}$ and thence $2.5 \mathrm{~km}$ simulations (domains shown in Fig. 2). The top boundary condition within all three domains made use of the Base Case or Opt1_Dyn_Extrap2_Wosp methodologies. All domains use the same vertical layering structure in GEM, and also in AURAMS. The GEM meteorological parameterizations change going to higher resolution, to account for the now-explicit resolution of convective processes. Surface ozone measurements (5 min sampling), obtained using a local mesonet during the BAQS-Met study, were averaged to hourly values (Fig. 8). The surface ozone concentrations in the study region are strongly affected by lake- and land-breeze circulations (Makar et al., 2010): the summary statistics for the two runs are compared here to determine the relative impact of the modified boundary conditions (indirectly, through transfer on the lateral boundary, and directly, through the top boundary) on the very local ozone predictions. Table 4 summarizes the comparison for the different metrics and statistical measures. Bold-face numbers within the table identify which of the two high resolution simulations (Base Case or Opt1_Dyn_Extrap2_Wosp) had the better score. For this small subdomain, the original Base Case had better MB and NMB scores for the hourly average ozone, the daily mean ozone, and the daily $1 \mathrm{~h}$ minimum ozone than the Opt1_Dyn_Extrap2_Wosp scenario, but the latter had better $R$ and RMSE values. For the daily 1-h maximum ozone, the Opt1_Dyn_Extrap2_Wosp scenario outperformed the Base Case for all metrics. These results show that the choice of ozone climatology methodology can have a significant impact even at the local scale (through the lateral transfer from lower-resolution domains, and through the top boundary condition). From the forecasting standpoint, accurate prediction of the maximum ozone is of key importance: the Opt1_Dyn_Extrap2_Wosp scenario significantly improves the model results, relative to the Base Case.

The above analysis suggests that the best overall performance, both at the surface and throughout the profile, is obtained through using the methodology which combines the use of dynamic ozone climatology, no sponge zone at the model top, extrapolation of the existing climatology to $50 \mathrm{mb}$, and no mass consistency correction in the wind fields (methodology Opt1_Dyn_Extrap2_Wosp). Two further analyses of case studies follow, comparing this recommended methodology to the Base Case, at higher resolution.

Figure 9 shows example ozone time series from the Bear Creek site $\left(42.54^{\circ} \mathrm{N}, 82.39^{\circ} \mathrm{W}\right)$; the improvement to the magnitude of the peak values and the overall fit to the observations being noticeable in both examples.

\section{Case study 2: AURAMS simulations over the Rockies compared to local Mesonet, summer 2002}

This second case study was chosen to analyse the persistent positive bias just east of the Canadian Rockies noticeable in the kriged mean bias surfaces in all of the simulations of Fig. 5. This region is of particular interest from the standpoint of ozone forecasting in Canada, due to the known occurrence of stratosphere/troposphere exchange events in the measurement record (cf. Chung and Dann, 1985). The period simulated was 8 June to 31 August 2002, and the $36 \mathrm{~km}$ and $12 \mathrm{~km}$ domains used in the simulations are shown in Fig. 10. These simulations made use of GEM version 3.2.0 $(353 \times 415$ grid points over the globe, with $270 \times 353$ grid points over North America, $0.22^{\circ}$ or approximately $24 \mathrm{~km}$ 
Table 4. Ozone statistics for 10 BAQS-Met and OME surface ozone monitoring sites in southern Ontario during the summer of 2007, comparing Base Case and Opt1_Dyn_Extrap2_Wosp simulations to observations, $2.5 \mathrm{~km}$ grid spacing domain. The run with the better value is shown in bold face, for each metric. M_obs: mean observed value, M_mod: mean model value, MB: mean bias, NMB: normalized mean bias, $R$ : correlation coefficient, RMSE: Root Mean Square Error.

\begin{tabular}{|c|c|c|c|c|c|c|c|c|}
\hline \multirow{2}{*}{ Statistic } & \multicolumn{2}{|c|}{$\mathrm{O}_{3}$ hourly averages } & \multicolumn{2}{|c|}{$\mathrm{O}_{3}$ daily mean } & \multicolumn{2}{|c|}{$\mathrm{O}_{3}$ daily 1-h max } & \multicolumn{2}{|c|}{$\mathrm{O}_{3}$ daily 1-h min } \\
\hline & Base & Opt $1_{\ldots} \ldots$ & Base & Opt $1_{\ldots} \ldots$ & Base & Opt $1_{\ldots} \ldots$ & Base & Opt $1 \ldots$ \\
\hline M_obs (ppbv) & \multicolumn{2}{|c|}{41.1} & \multicolumn{2}{|c|}{41.8} & \multicolumn{2}{|c|}{63.2} & \\
\hline M_mc & 41.1 & 37.4 & 41.8 & 38.1 & 66.6 & 61.2 & 21.0 & 18.7 \\
\hline & 0.0 & & & & & & & \\
\hline $\mathrm{NM}$ & 0.00 & -0.09 & 0.001 & -0.090 & 0.066 & 31 & -0.02 & -0.132 \\
\hline$R$ & 0.59 & 0.63 & 0.53 & 0.60 & 0.51 & 0.57 & 0.57 & 0.60 \\
\hline RMSE (ppbv) & 19.3 & 17.6 & 14.8 & 13.2 & 20.3 & 17.9 & 14.1 & 13.2 \\
\hline
\end{tabular}

Table 5. Ozone statistics for 23 surface ozone monitoring network sites in Alberta, summer 2002, comparing Base Case and Opt1_Dyn_Extrap2_Wosp, $12 \mathrm{~km}$ grid spacing domain. The run with the better value is shown in bold face, for each metric. M_obs: mean observed value, M_mod: mean model value, MB: mean bias, NMB: normalized mean bias, $R$ : correlation coefficient, RMSE: Root Mean Square Error.

\begin{tabular}{|c|c|c|c|c|c|c|c|c|}
\hline \multirow[t]{2}{*}{ Statistic } & \multicolumn{2}{|c|}{$\mathrm{O}_{3}$ hourly averages } & \multicolumn{2}{|c|}{$\mathrm{O}_{3}$ daily mean } & \multicolumn{2}{|c|}{$\mathrm{O}_{3}$ daily 1-h $\max$} & \multicolumn{2}{|c|}{$\mathrm{O}_{3}$ daily $1-\mathrm{h}$ min } \\
\hline & Base & Opt $1_{-\ldots}$ & Base & Opt $1_{-\ldots}$ & Base & Opt $1_{-\ldots}$ & Base & Opt $1_{\ldots} \ldots$ \\
\hline M_obs (ppbv) & \multicolumn{2}{|c|}{27.19} & \multicolumn{2}{|c|}{26.73} & \multicolumn{2}{|c|}{42.07} & \multicolumn{2}{|c|}{10.65} \\
\hline M_mod (ppbv) & 31.50 & 28.64 & 30.99 & 28.18 & 50.62 & 46.25 & 10.10 & 9.32 \\
\hline MB (ppbv) & 4.31 & 1.45 & 4.34 & 1.48 & 8.69 & 4.25 & -0.56 & -1.35 \\
\hline $\mathrm{NMB}$ & 0.159 & 0.053 & 0.160 & 0.054 & 0.203 & 0.099 & -0.052 & -0.125 \\
\hline$R$ & 0.691 & 0.683 & 0.627 & 0.603 & 0.576 & 0.563 & 0.338 & 0.321 \\
\hline RMSE (ppbv) & 15.44 & 13.66 & 10.44 & 8.93 & 18.11 & 15.30 & 9.73 & 9.31 \\
\hline
\end{tabular}

grid spacing in the core region, $450 \mathrm{~s}$ time step) to provide the driving meteorology. The same version of AURAMS as the previous tests was used. The $24 \mathrm{~km}$ GEM meteorology was used to drive both the $36(80 \times 105$ grid points $)$ and the $12 \mathrm{~km}$ (75 × 115 gridpoints) AURAMS simulations.

Figure 11 shows the locations of the 23 surface mesonet observation sites used for statistical evaluation, and an ozonesonde release site. The analysis which follows is based on the $12 \mathrm{~km}$ domain simulations.

Table 5 shows the comparison results for the same statistical quantities as Table 4 for this second case study. Both simulations have positive mean biases, normalized mean biases, and root mean square errors, but these are greatly reduced in the Opt1_Dyn_Extrap2_Wosp scenario compared to the base case. Mean biases and normalized mean biases are reduced by more than a factor of two, and RMSE values are reduced by more than $1.5 \mathrm{ppbv}$, for all metrics. Correlation coefficients have decreased slightly with the use of the new dynamic boundary condition. As in the simulations examined in the previous sections, the adoption of the new boundary condition methodology significantly improves the model performance.

Figure 12 compares the kriged daily 1 -h surface maximum ozone mean bias values between the two simulations.
The use of the Opt1_Dyn_Extrap2_Wosp boundary conditions (Fig. 12b) reduces the overall negative bias relative to the base case (Fig. 12a), though positive bias regions remain. These regions, like those for the simulations shown earlier (see Fig. 5h), are centered on major industrial areas (from south-west to north-east these are the cities of Calgary, Red Deer, Edmonton, and the Oil Sands (see Fig. 11 for locations), suggesting that at least part of the remaining biases may be the result of errors in the anthropogenic ozone formation processes, as opposed to boundary condition-dominated causes.

Figure 13a compares modelled and measured surface ozone concentrations at the Edmonton East station during a series of high ozone days between 9 and 15 July. Overall, the new methodology gives a closer fit to the observations, though the maximum during the time period (11 July) was better simulated by the Base Case.

An examination of the time series at different monitoring stations suggested that one troposphere/stratosphere mixing event may be responsible for part of the remaining positive biases in both simulations. Figure $13 \mathrm{~b}$ compares the observations and the two model-simulated ozone concentrations at Steeper station, with the event in question occurring between 11 June and 14 June. Two stages in the 


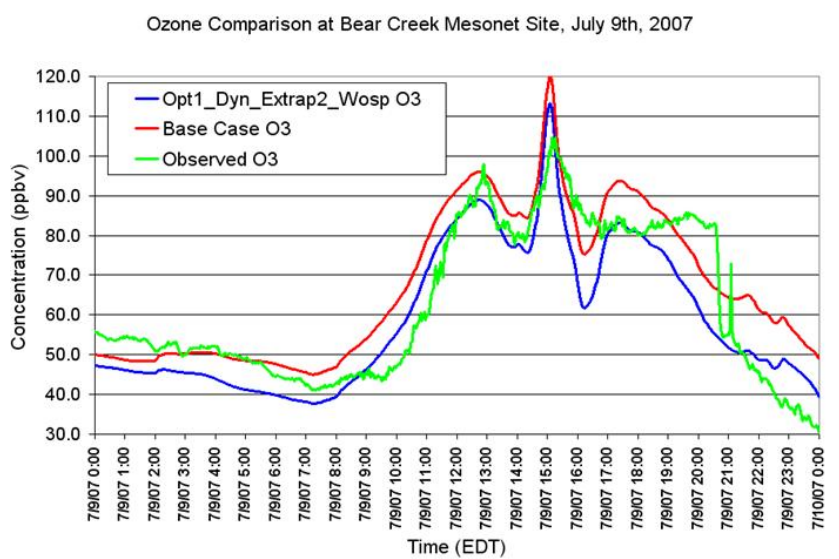

Ozone Comparison at Bear Creek Mesonet Site, July 10th, 2007

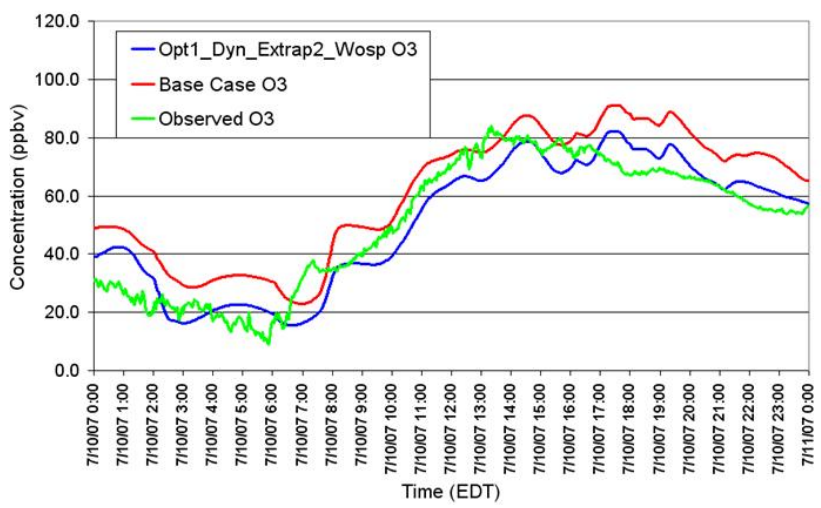

Fig. 9. Example observed (green), Base Case (red), and Opt1_Dyn_Extrap2_Wosp ("New"; blue) high resolution simulations; (a) 9 July, (b) 10 July.

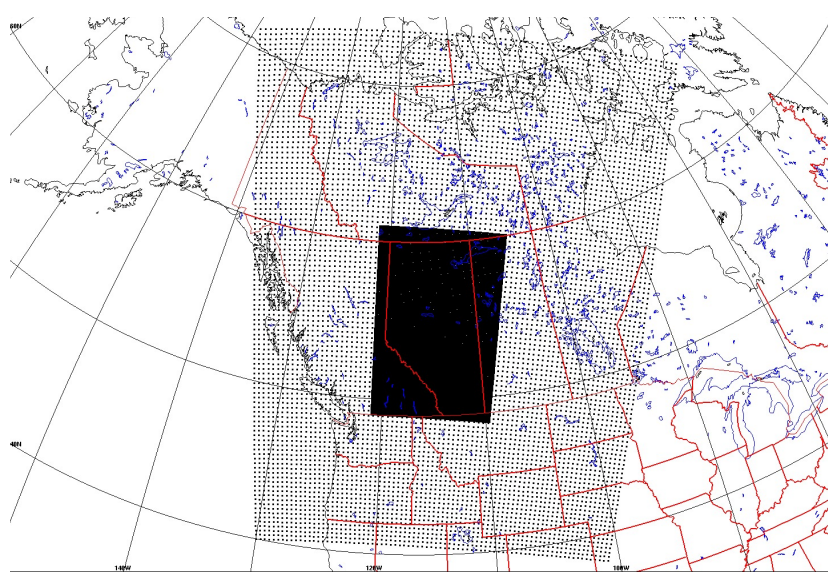

Fig. 10. 36- and 12-km domains, summer 2002 simulations over western Canada.

model transport resulted in the simulated event. The first stage was the passage of an upper low, with an associated ridge creating a deep layer of subsidence, with downward vertical velocities extending from as high as $10000 \mathrm{~m}$ to the surface, over central Alberta, northern Alberta, and

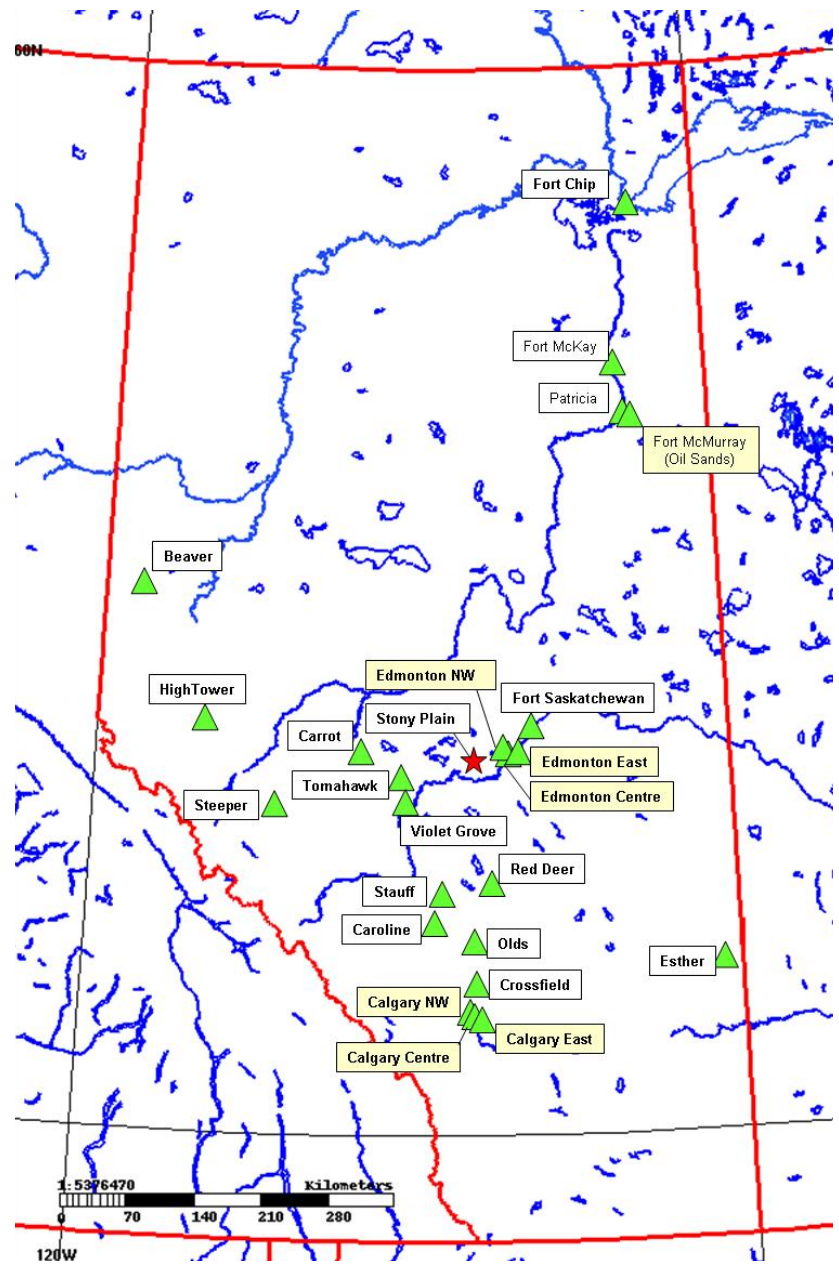

Fig. 11. Mesonet (green triangles) and ozonesonde location (red star), western Canada summer 2002 simulations. City and Oil Sands sites identified with yellow text boxes.

Saskatchewan. This first stage resulted in 150 to $200 \mathrm{ppbv}$ ozone at the $3000 \mathrm{~m}$ a.g.l. (above ground level). The second stage was the creation of a deep surface-based unstable planetary boundary layer (due to daytime heating), behind the passing upper low. The turbulent mixing associated with this second stage allowed the model-simulated ozone to reach the surface. This final stage of the transport has a strong diurnal trend, with mixing to the surface ceasing in the evening. Tephigrams, derived from rawinsondes launched at the Stony Plain site west of Edmonton (Fig. 11, star symbol) confirm the presence of the deep well-mixed layer up to $3200 \mathrm{~m}$ on 12 and 13 June, but this weakened to $2200 \mathrm{~m}$ on 14 June. Observed and simulated ozonesonde values at Stony Plain (Fig. 14) show the presence of high concentration ozone at $6000 \mathrm{~m}$. Both simulations are biased low above $5500 \mathrm{~m}$, the base-case has positive biases below $5500 \mathrm{~m}$, while the Opt1_Dyn_Extrap2_Wosp simulation has lower positive or negative biases below $5500 \mathrm{~m}$. The location of the observed mid-troposphere ozone peak in the profile 


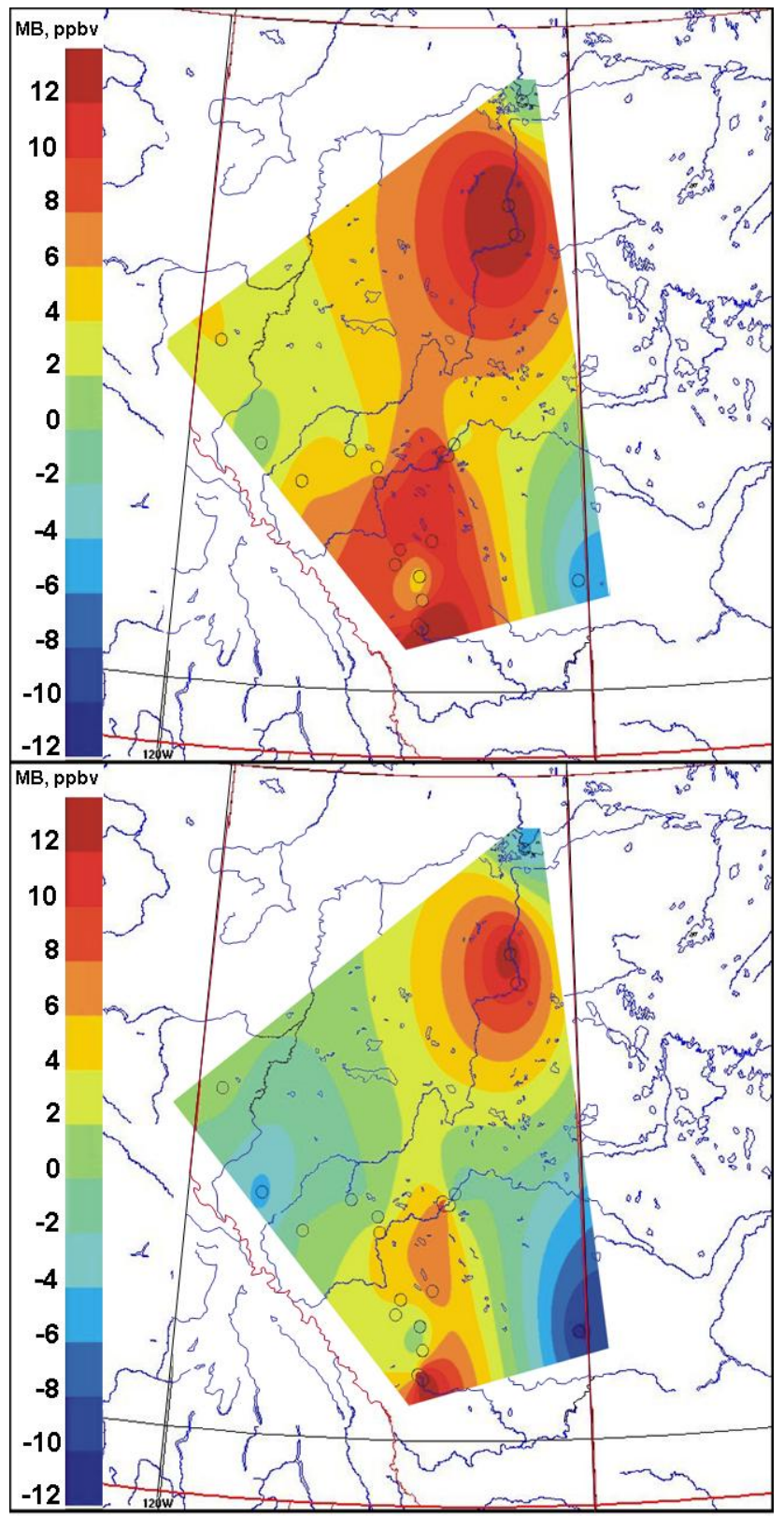

Fig. 12. Kriged surface daily $1 \mathrm{hr}$ maximum ozone, western Canada summer 2002 simulations.

(a) Base Case, (b) Opt1_Dyn_Extrap2_Wosp scenario.

associated with the event at $5800 \mathrm{~m}$ is well predicted by the Opt1_Dyn_Extrap2_Wsop methodology, but its magnitude is biased low for both simulations. Given the negative biases in the upper free troposphere, the remaining model positive biases at the surface during this event are thus likely due to the simulated boundary layer being less stable than the ambient atmosphere, on 14 and 15 June. The event illustrates the importance of the timing and strength of the coupling of upper level and lower level ozone transport to the middle Troposphere, during STE events.
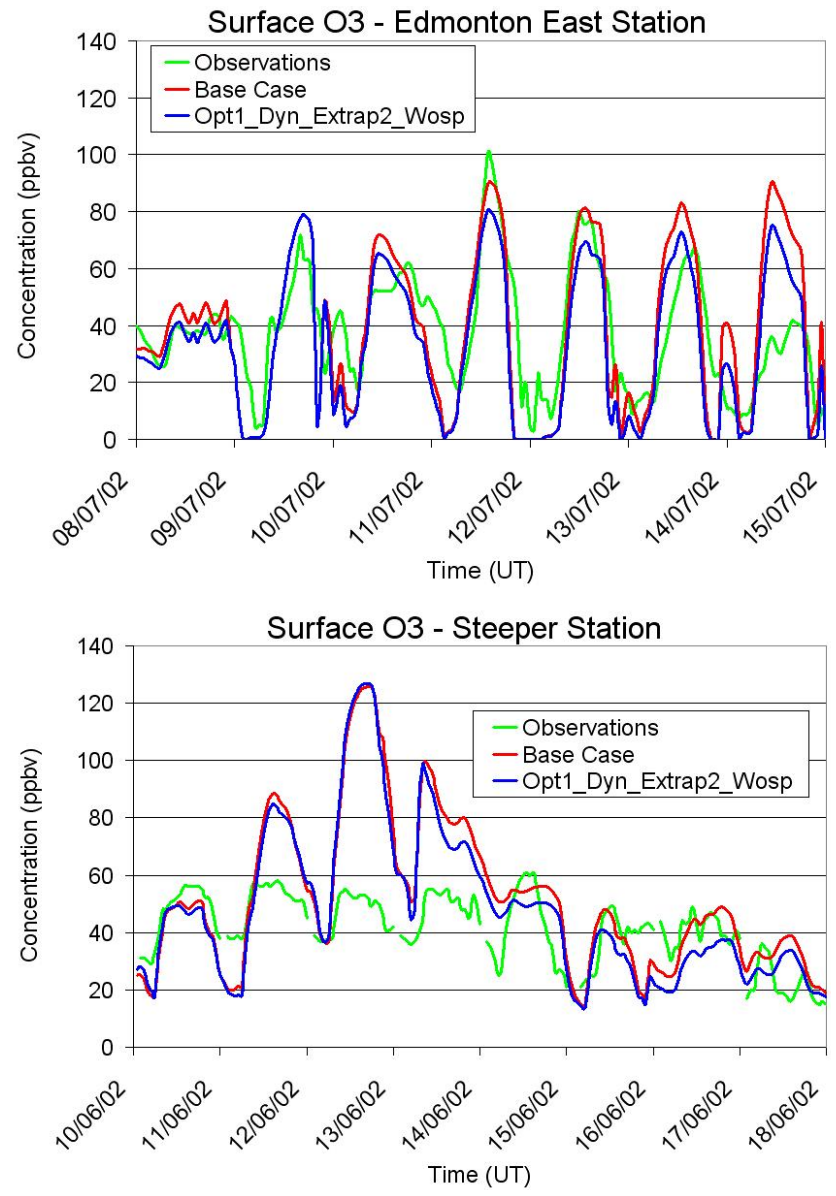

Fig. 13. Time series of ozone at (a) Edmonton East, showing typical comparison between model and observations, 8 to 15 July 2002. (b) Comparison during downward mixing event, 10 to 18 June 2002.

Stony Plain Ozonesonde, $12 Z$ June 12, 2002

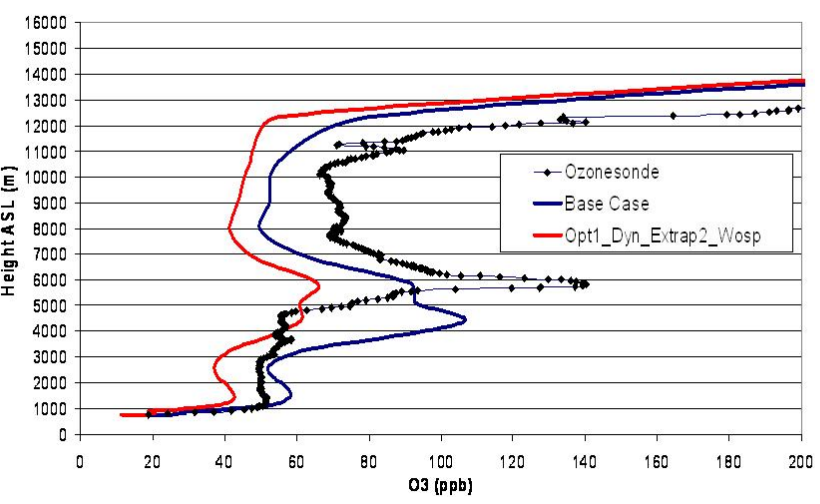

Fig. 14. Profile of ozone at Stony Plain, 12:00 Z, 12 June 2002. 


\section{Discussion and conclusions}

Our analysis shows that considerable improvements in model ozone simulation accuracy were achieved in our regional air-quality model through the careful choice of the methodology used to specify lateral and top boundary conditions from ozone climatologies. Substantial improvements were obtained by using dynamic tropopause-height adjustment of the ozone climatology in the vertical, by removing the top sponge zone, and by removing mass consistency corrections. Using extrapolation to extend the ozone climatology in the vertical also improved the fit to observations in the top part of the model domain. The improvements of this overall methodology were significant, particularly in the reduction of mean biases and RMSE for the lower resolution simulations, and improving correlation coefficients and RMSE at higher resolutions (and for all statistical measures, at high resolution). Examination of a case study along the Rocky Mountains has suggested that the degree of coupling between the planetary boundary layer and the free troposphere is a key factor in determining the extent to which stratosphere-origin ozone is brought to the surface.

It should be noted that other combinations and permutations of methodologies tested here are possible, and the impact of an individual component of a combined methodology will vary for different levels of the atmosphere.

One surprising outcome of the work was that all three of the mass consistency corrections examined, resulted in excessive downward transport of ozone downwards from the upper part of the model. The best model performance for surface ozone resulted from the use of a methodology combining a vertical velocity mass consistency correction, the absence of sponge zone at the model top, and extrapolation of the ozone climatology above $100 \mathrm{mb}$. However, we also demonstrate the fallacy of using surface observations alone for model evaluation of ozone; the comparison to BAQS-Met ozonesondes showed that this improved performance at the surface came at the expense of large positive biases in ozone concentrations in the middle to upper troposphere, precluding the use of this method in our subsequent high-resolution analysis.

It is important to note that at least some of these results may depend on the particular combination of meteorological model and CTM grids and grid projections, as well as their respective vertical coordinates and resolutions, the advection algorithm employed, and the height of the model top. AURAMS has relatively low resolution in the vicinity of the model top compared to the driving meteorological model GEM (Fig. 3); this may result in larger errors in the mass consistency corrections than might have been the case had the two models used the same vertical and horizontal coordinate system. Similarly, models having a top below the typical climatological tropopause height (approximately $10 \mathrm{~km}$, here) would be less likely to be affected by the downward ozone transport related to mass consistency. AURAMS makes use of a domain-wide mass conservation correction subsequent to mass consistency corrections; the former may help constrain the model mass when the latter was absent.

Nevertheless, the methodologies quoted from the literature and tested here were intended for use with any combination of air-quality and meteorological models; in our particular combination, specifically for ozone simulations, some of these methodologies resulted in erroneously high ozone concentrations throughout the troposphere. Further research is needed with coupled meteorological/air-quality models in order to determine whether differences between the meteorological and air-quality model grids used here resulted in the increase in middle and upper troposphere ozone bias with the use of mass consistency corrections. We also note the importance of the use of ozone observations in the vertical dimension in model evaluation; the use of surface ozone concentrations alone may mask deficiencies in the methodologies employed.

The concept of dynamic, tropopause-referenced adjustments to climatological ozone boundary conditions has been introduced here and has been shown to have a significant improvement on surface ozone prediction accuracy. The algorithm used here is relatively simple - future research on the specification of ozone boundary conditions from ozone climatologies should attempt to resolve the median and extreme-event ozone climatology, as well as the more traditional average, and consider the removal of seasonal and synoptic variations (cf. Thouret et al., 2006), and examine the use of surrogate fields such as potential vorticity as proxies for setting ozone boundary conditions. Here, we have examined the impacts of variations in boundary condition methodology for the summer season. These impacts may well be stronger in the spring, when stratosphere/troposphere exchange events are known to maximize, and spring-time simulations and comparison with observations would be a worthwhile expansion of the work performed here. The use of improved climatological data would likely improve model performance in a similar manner to the model-internal corrections shown here.

Acknowledgements. The authors would like to acknowledge the financial support of Environment Canada and the Ontario Ministry of the Environment for the BAQS-Met study. We gratefully acknowledge the assistance of the AIRNow program and its participating stakeholders in providing near-real-time ground-level ozone observations across North America.

Edited by: D. Hastie 


\section{References}

Birner, T., Sankey, D., and Shepherd, T. G.: The Tropopause inversion layer in models and analyses, Geophys. Res. Lett., 33, L14804, doi:10.1029/2006GL026549, 2006.

Brost, R. A.: The sensitivity to input parameters of atmospheric concentrations simulated by a regional chemical model, J. Geophys. Res., 93, 2371-2387, 1987.

Byun, D. W.: Dynamically consistent formulations in meteorological and air quality models for multiscale atmospheric studies, Part I: governing equations in a generalized coordinate system, J. Atmos. Sci., 56, 3789-3807, 1999a.

Byun, D. W.: Dynamically consistent formulations in meteorological and air quality models for multiscale atmospheric studies, Part II: mass conservation issues, J. Atmos. Sci., 56, 3808-3820, 1999b.

CEP: Carolina Environmental Program, Sparse Matrix Operator Kernel Emission (SMOKE) modelling system, University of North Carolina, Carolina Environmental Programs, Chapel Hill, NC, http://www.smoke-model.org/index.cfm, last access: 14 September 2010, 2003.

Chang, J. S., Jin, S., Li, Y., Beauharnois, M., Lu, C.-H., Huang, H.-C., Tanrikulu, S., and Da Massa, J.: The SARMAP air quality model. Final Report, SJVAQS/AUSPEX, Regional Modeling Adaptation Project, Available from California Air Resources Board, 2020 L. Street, Sacremento, CA 95814, 53 pp., 1997.

Chen, K. S., Ho, Y. T., Lai, C. H., and Chou, Y.-M.: Photochemical modeling and analysis of meteorological parameters during ozone episodes in Kaohsiung, Taiwan, Atmos. Environ., 37(13), 18111823, 2003.

Cho, S., Makar, P. A., Lee, W. S., Herage, T., Liggio, J., Li, S. M., Wiens, B., and Graham, L.: Evaluation of a unified regional airquality modeling system (AURAMS) using PrAIRie2005 field study data: The effects of emissions data accuracy on particle sulphate predictions, Atmos. Environ., 43, 1864-1877, 2009.

Chung, Y. S. and Dann, T.: Observations of stratospheric ozone at the ground level in Regina, Canada, Atmos. Environ., 19, 157$162,1985$.

Côté, J., Gravel, S.,Méthot, A., Patoine, A., Roch, M., and Staniforth, A.: The operational CMC-MRB Global Environmental Multiscale (GEM) model, Part 1: Design considerations and formulation, Mon. Weather Rev., 126, 1373-1395, 1998.

Gong, W., Dastoor, A. P., Bouchet, V. S., Gong, S. , Makar, P. A., Moran, M. D., Pabla, B., Ménard, S., Crevier, L.-P., Cousineau, S., and Venkatesh, S.: Cloud processing of gases and aerosols in a regional air quality model (AURAMS), Atmos. Res., 82, 248275, 2006.

Gong, W., Makar, P. A., and Moran, M. D.: Mass-conservation issues in modelling regional aerosols, Proc. $26^{\text {th }}$ NATO/CCMS ITM on Air Pollution Modelling and Its Application, 26-29 May, Istanbul, Turkey, in: Air Pollution Modelling and Its Application XVI, edited by: Borrego, C. and Incecik, S., Kluwer/Plenum Publishers, New York, 383-391, 2003.

He, H., Tarasick, D. W., Hocking, W. K., Carey-Smith, T. K., Rochon, Y., Zhang, J., Makar, P. A., Osman, M., Brook, J., Moran, M., Jones, D., Mihele, C., Wei, J. C., Osterman, G., Argall, P. S., McConnell, J., and Bourqui, M. S.: Transport analysis of ozone enhancement in Southern Ontario during BAQS-Met, Atmos. Chem. Phys. Discuss., 10, 15559-15593, doi:10.5194/acpd-1015559-2010, 2010.
Holton, J. R., Haynes, P. H., McIntyre, M. E., Douglass, A. R., Rood, R. B., and Pfister, L.: Stratosphere-troposphere exchange, Rev. Geophys., 33, 403-440, 1995.

Houyoux, M. R., Vukovich, J. M., Coats Jr., C. J., and Wheeler, N. J. M.: Emission inventory development and processing for the Seasonal Model for Regional Air Quality (SMRAQ) project, J. Geophys. Res., 105, 9079-9090, 2000.

Hu, Y., Odman, M. T., and Russell, A. G.: Mass conservation in the Community Multiscale Air Quality model, Atmos. Environ., 40, 1199-1204, 2006.

Jiménez, P., Parra, R., and Baldasano, J. M.: Influence of initial and boundary conditions for ozone modeling in very complex terrains: A case study in the northeastern Iberian Peninsula, Environ. Model. Softw., 22(9), 1294-1306, 2007.

Lee, S. M., Lee, S. M., Yoon, S. C., and Byun, D. W.: The effect of mass inconsistency of the meteorological field generated by a common meteorological model on air quality modeling, Atmos. Environ., 38, 2917-2926, 2004. .

Logan, J. A.: An analysis of ozonesonde data for the troposphere: Recommendatioins for testing 3-D models, and development of a gridded climatology for tropospheric ozone, J. Geophys. Res., 104, 16115-16149, 1999.

Makar, P. A., Moran, M. D., Zheng, Q., Cousineau, S., Sassi, M., Duhamel, A., Besner, M., Davignon, D., Crevier, L.-P., and Bouchet, V. S.: Modelling the impacts of ammonia emissions reductions on North American air quality, Atmos. Chem. Phys., 9, 7183-7212, doi:10.5194/acp-9-7183-2009, 2009.

Makar, P. A., Zhang, J., Gong, W., Stroud, C., Sills, D., Hayden, K. L., Brook, J., Levy, I., Mihele, C., Moran, M. D., Tarasick, D. W., and He, H.: Mass tracking for chemical analysis: the causes of ozone formation in southern Ontario during BAQSMet 2007, Atmos. Chem. Phys. Discuss., 10, 14241-14312, doi:10.5194/acpd-10-14241-2010, 2010.

Mathur, R., Shankar, U., Hanna, A. F., Odman, M. T., McHenry, J. N. , Coats Jr., C. J., Alapaty, K., Xiu, A., Arunachalam, S., Olerud Jr., D. T., Byun, D. W., Schere, K. L., Binkowski, F. S., Ching, J. K. S., Dennis, R. L., Pierce, T. E., Pleim, J. E., Roselle, S. J., and Young, J. O.: Multiscale Air Quality Simulation Platform (MAQSIP): Initial applications and performance for tropospheric ozone and particulate matter, J. Geophys. Res., 110, D13308, doi:10.1029/2004JD004918, 2005.

Mena-Carrasco, M., Tang, Y., Carmichael, G. R., Chai, T., Thongbongchoo, N., Campbell, J. E., Kulkarni, S., Horowitz, L., Vukovich, J., Avery, M., Brune, W., Dibb, J. E., Emmons, L., Flocke, F., Sachse, G. W., Tan, D., Shetter, R., Talbot, R. W., Streets, D. G., Frost, G., and Blake, D.: Improving regional ozone modeling through systematic evaluation of errors using the aircraft observations during the International Consortium for Atmospheric Research on Transport and Transformation, J. Geophys. Res., 112, D12S19, doi:10.1029/2006JD007762, 2007.

NASA: http://mtp.jpl.nasa.gov/products/products.html, last access: 14 September, 2010.

Odman, M. T. and Russell, A. G.: Mass conservative coupling of non-hydrostatic meteorological models with air quality models, in: Air Pollution Modeling and its Application XIII, edited by: Gryning, S.-E. and Batchvarova, E., Kluwer/Plenum, New York, 651-660, 2000.

Priestley, A: A quasi-conservative version of the semi-Lagrangian advection scheme, Mon. Weather Rev.,121, 621-629, 1993. 
Roe, J. M. and Jasperson, W. H.: A new Tropopause definition from simultaneous ozone-temperature profiles, Interim Technical Report 1, 1 July 1979-1 July 1980, Control Data Corporation, Minneapolis Research Division, 16 pp., 1980.

Samaali, M., Moran, M. D., Bouchet, V. S., Pavlovic, R., Cousineau, S., and Sassi, M.: On the influence of chemical initial and boundary conditions on annual regional air quality model simulations for North America, Atmos. Environ., 43(32), 48734885, 2009.

Smyth, S. C., Jiang, W., Roth, H., Moran, M. D., Makar, P. A., Yang, F., Bouchet, V. S., and Landry, H.: A comparative performance evaluation of the AURAMS and CMAQ air quality modelling systems, Atmos. Environ., 43, 1059-1070, 2009.

Song, C.-K., Byun, D. W., Pierce, R. B., Alsaadi, J. A., Schaack, T. K., and Vukovich, F.: Downscale linkage of global model output for regional chemical transport modeling: Method and general performance, J. Geophys. Res., 113, D08308, doi:10.1029/2007JD008951, 2008.

Szopa, S., Foret, G., Menut, L., and Cozic, A.: Impact of large scale circulation on European summer surface ozone and consequences for modelling forecast, Atmos. Environ., 43, 11891195, 2009.

Tang, Y., Lee, P., Tsidulko, M., Huang, H.-C., McQueen, J. T., DiMego, G. J., Emmons, L. K., Pierce, R. B., Thompson, A. M., Lin, H.-M., Kang, D., Tong, D., Yu, S., Mathur, R., Pleim, J. E., Otte, T. L., Pouliot, G., Young, J. O., Schere, K. L., Davidson, P.M ., and Stajner, I.: The impact of chemical lateral boundary conditions on CMAQ predictions of tropospheric ozone over the continental United States, Environ. Fluid Mech., 9(1), 43-58, 2009.

Tang, Y., Carmichael, G. R., Thongboonchoo, N., Chai, T., Horowitz, L. W., Pierce, R. B., Al-Saadi, J. A., Pfister, G., Vukovich, J. M., Avery, M. A., Sachse, G. W., Ryerson, T. B., Holloway, J. S., Atlas, E. L., Flocke, F. M., Weber, R. J., Huey, L. G., Dibb, J. E., Streets, D. G., and Brune, W. H.: Influence of lateral and top boundary conditions on regional air quality prediction: A multiscale study coupling regional and global chemical transport models, J. Geophys. Res., 112(D10), D10S18, doi:10.1029/2006JD007515, 2007.
Tarasick, D. W., Moran, M. D., Thompson, A. M., Carey-Smith, T., Rochon, Y., Bouchet, V. S., Gong, W., Makar, P. A., Stroud, C., Ménard, S., Crevier, L.-P., Cousineau, S., Pudykiewicz, J. A., Kallaur, A., Moffet, R., Ménard, R., Robichaud, A., Cooper, O. R., Oltmans, S. J., Witte, J. C., Forbes, G., Johnson, B. J., Merrill, J., Moody, J. L., Morris, G., Newchurch, M. J., Schmidlin, F. J., and Joseph, E.: Comparison of Canadian air quality forecast models with tropospheric ozone profile measurements above midlatitude North American during the IONS/ICARTT campaign: Evidence for stratospheric input, J. Geophys. Res.Atmos.s, 112, D12S22, doi:10.1029/2006JD007782, 2007.

Thouret, V., Cammas, J.-P., Sauvage, B., Athier, G., Zbinden, R., N'edélec, P., Simon, P., and Karcher, F.: Tropopause referenced ozone climatology and inter-annual variability (1994-2003) from the MOZAIC programme, Atmos. Chem. Phys., 6, 1033-1051, doi:10.5194/acp-6-1033-2006, 2006.

Tong, D. Q. and Mauzerall, D. L.: Spatial variability of summertime tropospheric ozone over the continental United States: Implications of an evaluation of the CMAQ model, Atmos. Environ., 40(17), 3041-3056, 2006.

van Loon, M., Vautard, R., Schaap, M., Bergström, R., Bessagnet, B., Brandt, J., Builtjes, P. J. H., Christensen, J. H., Cuvelier, C., Graff, A., Jonson, J. E., Krol, M., Langner, J., Roberts, P., Rouil, L., Stern, R., Tarrasón, L., Thunis, P., Vignati, E., White, L., and Wind, P.: Evaluation of long-term ozone simulations from seven regional air quality models and their ensemble, Atmos. Environ., 41(10), 2083-2097, 2007.

Winner, D. A., Cass, G. R., and Harley, R. A.: Effect of alternative boundary conditions on predicted ozone control strategy performance: A case study in the Los Angeles area, Atmos. Environ., 29(23), 3451-3464, 1995.

WMO: International meteorological vocabulary. WMO, No. 182, TP. 91, Geneva Secretariat of the World Meteorological Organization, Pp. xvi, 276, 1966.

Yamartino, R. J.: Nonnegative, Conserved Scalar Transport Using Grid-Cell-centered, Spectrally Constrained Blackman Cubics for Applications on a Variable-Thickness Mesh, Mon. Weather Rev., 121, 753-763, 1993.

Yu, S., Mathur, R., Schere, K., Kang, D., Pleim, J., and Otte, T. L.: A detailed evaluation of the Eta-CMAQ forecast model performance for $\mathrm{O}_{3}$, its related precursors, and meteorological parameters during the 2004 ICARTT study, J. Geophys. Res., 112, D12S14, doi:10.1029/2006JD007715, 2007. 